\title{
Teatro y texto en el primer renacimiento español. Del teatro al manuscrito e impreso
}

\author{
Javier San José Lera \\ Universidad de Salamanca ${ }^{1}$ \\ trujaman@usal.es
}

Recepción: 15/03/2013, Aceptación: 25/06/2013,Publicación: 20/12/2013

\section{Resumen}

La consideración de algunas de las circunstancias de la fijación de los textos teatrales en el silencioso mundo del manuscrito o el impreso muestra el proceso de pérdida implicado en la «institucionalización» de un género concebido inicialmente para el bullicioso espacio de la representación.

Este trabajo repasa algunos de los mecanismos implicados en el paso del teatro representado al texto fijado en manuscritos o impresos referentes al teatro español de la primera mitad del siglo XVI.

Palabras clave

Teatro; representación; texto; siglo xvI; manuscrito; impreso

\begin{abstract}
Theatre and text in first spanish renaissance: From theater to manuscript and printed edition The analysis of various circumstances related to how theatrical texts were fixed in the silent realm of manuscripts or printed books shows the losses entailed by the «institutionalization» of a genre that was originally conceived for noisy stages.

This paper reviews some of the mechanisms by which theatrical performances become manuscripts or printed books through the first half of the 16th century Spanish drama.
\end{abstract}

Keywords

Theater; Play; Text; 16th century; manuscript; printed books

1. Este trabajo se ha realizado en el marco del proyecto de investigación TESAL16. Documentación, edición, estudio y propuestas de repre- sentación del teatro del siglo XVI en Salamanca (Junta de Castilla y León SA155A11-1 y MICINN FFI2011-25582). 
En el Prohemio a los discretos lectores de la Propalladia, Torres Naharro justifica la impresión de sus obras de la siguiente manera: «que las más destas obrillas andavan ya fuera de mi obediencia y voluntad». ${ }^{2}$ La idea de recoger los textos, expósitos y maltratados, en un impreso, es un tópico prohemial de las dedicatorias. Junto con los de humildad y buena voluntad, que también esgrime Torres, los podemos leer ya en la dedicatoria del Cancionero de Juan del Enzina (1496) a los Duques de Alba, y en ámbito estrictamente teatral, en los preliminares de tantas impresiones de partes de comedia del siglo XviI; ${ }^{3}$ pero más allá de ello, pone en evidencia una circulación previa amplia de las obras. En el caso de los textos teatrales esa circulación previa puede referirse bien a su recepción por un público lector a través de impresos (o manuscritos), bien por un público espectador; si de la primera no quedan testimonios anteriores a 1517, de la segunda modalidad de circulación podemos suponer la representación de al menos algunas de las obras: la Trophea y quizá la Seraphina, la Tinellaria y la Jacinta ${ }^{4}$

Lo que es un hecho es que Torres Naharro en la reflexión teórica del Prohemio tiene presente tanto la lectura como la representación de sus obras; se comprueba esto de forma evidente en el momento en el que se refiere a la estructura externa en jornadas, concebidas como «descansaderos, de donde la comedia queda mejor entendida y rescitada» (sub. mío). ${ }^{5}$

La conciencia de trasladar a un espacio ajeno, el de la imprenta, la realidad «performativa» (valga el neologismo) del teatro, nos da pie para reflexionar en

2. Torres Naharro, (1994: 7). Gillet no anota nada al respecto de esta frase en su edición de la Propalladia (Gillet 1951). Sin embargo, hace un recorrido minucioso sobre la que denomina impresionante vida textual de Torres, con nueve ediciones colectivas y media docena o más de ediciones sueltas, hasta reconstruir el stemma de ediciones del siglo XVI en los capítulos dedicados a Bibliografía de su edición, (Gillet, 1943: 3-128). La presencia de ediciones de sueltas y de «Propalladias» en el taller sevillano de Jacobo y Juan Cromberger, la documenta Griffin, 1988 y 1998.

3. «Y también porque andavan ya tan corrompidas y usurpadas algunas obrezillas mías que como mensageras avía embiado adelante, que ya no mías mas agenas se podía llamar (...) no me pude sofrir viéndolas tan maltratadas, levantándoles falso testimonio, poniendo en ellas lo que yo nunca dixe ni me pasó por pensamiento...» (Juan del Enzina, Dedicatoria "A los yllustres y muy maníficos señores don Fadrique de Toledo y doña Ysabel Pimentel Duques de Alva... Cancionero, 1496, fol. VIr y vo). En la dedicatoria a otro Duque de Alba, don Antonio, de su comedia El dómine Lucas (Vega, 1621: 138) escribe Lope: «... hallela en esta ocasión pidiendo limosna como las demás, tan rota, y desconoci$\mathrm{da}$, qual suelen estar los que salieron de su tierra para soldados con las galas y plumas de la nueva sangre, y buelven después de muchos ańos con una pierna de palo, medio braço, un ojo menos, y el vestido de la munición sin color determinada, hize por corregirla, y bien, o mal sale a luz, con el nombre del mayor amigo».

4. Plantea la posibilidad de representación de estas comedias Gillet (1961: 432); ver Joan Oleza (1998: 20-22). Pérez Priego recuerda que la Jacinta «fue representada a Isabella d'Este en uno de sus viajes a Roma» (Pérez Priego, 2011: 251).

5. Gillet (1951: 25) anota: «it will have to be referred logically not to actos, but to the implied intervals between the acts, the intermissions, which provide rest for the public as well as for the actors"; sobre el sentido de rescitada, como 'actuada' ver Gillet (1961:430). Ver también Melveena McKendrick (1989: 27). 
estas páginas sobre las implicaciones del diálogo entre texto teatral representado (o concebido para la representación) e impreso en el teatro del primer Renacimiento español. Este diálogo debe seguirse en dos direcciones: por un lado, desde el paso del espectáculo teatral y de su oralidad al texto y a la publicación, es decir, cómo se ha recogido la naturaleza espectacular del texto teatral en el impreso. Y por otro, en sentido inverso, es decir, las consecuencias del traslado del texto a la lectura que imagina la representación, con la necesidad de volver a leer los textos teatrales del xvi publicados en formato impreso, a la busca de aquello que ofrecen de potencialidad escénica, de posibilidad de transformarse en representación. ${ }^{6}$ Aquí me quiero ocupar de la primera de ellas. En términos generales se trata de una aplicación al estudio del teatro del siglo xvi de la doble naturaleza del teatro (como texto y como representación), «dicotomía no siempre valorada por la crítica», según opina Profeti (1996: 205); o la consideración del texto/escritura no frente a, sino en diálogo con el texto/escénico para la consecución del texto/teatro. ${ }^{7}$

En ese planteamiento que propongo es necesario tener en cuenta, como marco de reflexión general, la fructífera idea aplicada por Roger Chartier (1999) al distinguir entre la doble consideración del «texto" como "monumento" y como "evento", distinción especialmente útil para los textos literarios del teatro en los que confluye esa dicotomía ya señalada. Tradicionalmente los textos teatrales han sido considerados como textos pertenecientes a la «institución literaria» convencional con sus imposiciones culturales: texto fijado por escrito a través del manuscrito o la imprenta, destinado a un lector individual y silencioso a la busca de valores estéticos y de reconstrucción de sentidos. Como consecuencia, se han aplicado a ellos preferentemente las disciplinas que se encargan de consolidar la institución literaria así configurada: filología, historia literaria, estética, hermenéutica. ${ }^{8}$ Sin embargo, esta consideración «monumental» nos empuja a olvidar la dimensión de realización escénica que rodea por su naturaleza estos textos teatrales convirtiéndolos en "eventos». Un replanteamiento tal del texto nos obliga a poner en juego otras perspectivas para su consideración completa, conjugando la historia del teatro con la historia del libro y de la lectura y con la bibliografía material; al fin y al cabo, la impresión de textos teatrales se

6. "The historian may find some interest in the development of the stage as an institution" (Chambers, 1951, Preface: vii). La atención a este tipo de lectura y la consecuencia para la edición de textos teatrales puede verse en la propuesta escénica que hace Emilio de Miguel del Coloquio de Selvaggia de Juan de Vergara (Miguel Martínez, 2006).

7. (Profeti 1982: 162, n. 16). Con una mirada diferente de la que aquí planteo, se ha ocupa- do del estudio del impreso teatral Miguel M. García-Bermejo Giner (1998). El asunto del paso del teatro al impreso se ha estudiado brillantemente para el siglo Xviı por Germán Vega (2010), Florence d'Artois (2010) y Luigi Giuliani (2010).

8. La idea de que la imprenta fue responsable de la transición de la oralidad medieval a la lectura silenciosa fue difundida por H.J. Chaytor, (1967); la idea se discute en Saenger (1982). 
ha interpretado como una de las fuerzas constituyentes del teatro en el Renacimiento, y la relación entre teatro e imprenta como la manera en que se constata de forma más evidente en este momento la interacción entre texto y escena. ${ }^{9}$

En contexto español, esta doble naturaleza del texto teatral y la conciencia separada de representación y lectura en su paso al impreso se percibe, por ejemplo, en la epístola que encabeza la edición de las comedias de Lope de Rueda:

EPISTOLA SATISFATORIA de Juan Timoneda, al prudente lector.

Viniéndome a las manos, amantíssimo lector, las Comedias del excellente Poeta, y gracioso representante Lope de Rueda, me vino a la memoria el desseo y affectación que algunos amigos y señores míos tenían de vellas en la prouechosa y artificial emprenta. Por do me dispuse (con toda la vigilancia que fue possible) ponellas en orden, y sometellas baxo la correctión de la sancta madre yglesia. De las quales, por este respecto, se han quitado algunas cosas no lícitas y mal sonantes, que algunos en vida de Lope haurán oýdo. Por tanto miren que no soy de culpar, que mi buena intención es la que me salua (Rueda, 1576)

El traslado a la imprenta - un espacio nuevo para el teatro- permite esa licencia del editor para "ponellas en orden" (es decir, señalar parlamentos al margen y separarlos en párrafos), y suprimir aquello que se oyó en el rápido ajetreo de la escena, pero de lo que no es conveniente disponer - en beneficio de la corrección - en el reposo de la lectura. Es claro que leer y ver comedias son dos actividades diversas, como advertía también claramente el encargado de la aprobación de La dama boba, de Lope de Vega, Tomás Gracián Dantisco, al firmarla en Madrid el 27 de octubre de 1613, tal y como se lee en el folio final del manuscrito autógrafo de la obra: «Esta comedia intitulada la Dama Boba se podrá representar, reservando a la vista lo que fuera de la lectura se ofreciese y lo mismo en los cantares y entremés y bayles» (Vega, 1613: fol. 132). El censor aprueba lo que ha leído en el manuscrito, donde ha quedado instituido un texto, pero "fuera de la lectura", se reserva la opinión censora hasta ver que lo representado, el texto en su eventualidad representativa, se ajusta a lo leído.

Los textos teatrales del siglo xvi han seguido un camino de transmisión textual que, en cierta forma, establece una frontera con el teatro medieval, como explicó bien Miguel Ángel Pérez Priego (1998). ${ }^{10}$ «La obra dramática medieval no posee una realización textual propia»; los ceremoniales catedralicios, los libros de fábrica, de cuentas, etc. recogen noticias de espectáculos cuyos textos solamente de forma excepcional se han transmitido. Pero la inclusión por Enzina de sus églogas dramáticas en el Cancionero de 1496 cambia la situación e inicia la vida impresa del teatro. De su éxito editorial dan cuenta las sucesivas

9. Stone Peters, 2000 y 2004. Un planteamiento similar al que propongo sostiene el trabajo de Giuliani (2010).

10. Sobre la transmisión teatral impresa ver también Ana Vázquez Estévez, 1995. Para el teatro del siglo XviI, ver el trabajo de Germán Vega García-Luengos (2010) y los recogidos en el número 108 de Criticon. 
ediciones y el añadido de textos nuevos en los cancioneros posteriores de 1507 y 1509, (como ocurre igualmente con ediciones sucesivas de la Propalladia de Torres, que incluyen las comedias Calamita y Aquilana ausentes en la princeps de 1517). Por otra parte, es de imaginar la existencia de numerosas ediciones sueltas perdidas, así como de manuscritos que debieron recoger las piezas para su traslado a la imprenta o para su empleo en representaciones. ${ }^{11}$

Un caso de este tipo puede considerarse el interesante manuscrito 2621 de la Biblioteca Nacional de España, que contiene un cancionero con Poesías de varios autores, entre ellas la pieza teatral Farça a manera de visita de las damas valençianas, de Juan Fernández de Heredia, que debió representarse hacia 1524 en la corte de Valencia. ${ }^{12}$ La copia, en limpio y de letra clara, destaca en tinta roja el nombre de los interlocutores, tanto en el argumento inicial como en los márgenes o en el interior de las coplas, cuando el verso se distribuye en dos parlamentos (en ambos casos con abreviaturas, con algunas excepciones en que se añade al margen el nombre completo del personaje). Como rúbrica se destaca la didascalia explicita del texto: "Queda la señora sola», (Fernández de Heredia, 1524: fol 124v); otra didascalia más extensa, se copia en tinta negra, pero reduciendo el tamaño de los renglones en forma de triángulo invertido:

Entra un rey darmas de parte de otros çinco caualleros cô çinco pajes con sus lanças para los çinco q no las tenía y el Rey darmas haze su personaje cô el desafío de parte de los unos con la respuesta de los otros q cada uno haze y el Rey darmas les dize (Fernández de Heredia, 1524: fol 144r)

Como rúbricas se destacan igualmente los «villancicos» que forman parte de la obra y el anuncio de "quatro coplas a los maliciosos» de cierre (fol. 145v), con su «comparación» (fol 146r), así como el colofón «Fin» en el folio 146v. Tanto este uso de la rúbrica como la disposición del texto en la página, separando las tiradas de versos por coplas, y no por parlamentos de personajes, así como el inicio de cada copla con una mayúscula destacada en tamaño mayor y otra tinta más clara, nos hablan del modelo cancioneril que ha seguido el copista también

11. Sobre la conservación y pérdida de piezas teatrales es fundamental el catálogo de GarcíaBermejo, (1996). Sobre la «mise en page» del manuscrito teatral francés, ver Hasenohr (1990). En el proyecto digital Manos Teatrales (www. manosteatrales.org) los manuscritos teatrales fechados más antiguos son de 1581-82. Un manuscrito del Institut del Teatre, de la Comedia Sepúlveda, puede verse digitalizado en <http:// bib.cervantesvirtual.com/servlet/SirveObras /01478318770103173089079/index.htm> (consulta 29 de enero 2013); su descripción e historia en Vázquez Estévez (2003). Sobre el manuscrito de la Farsa de la Constanza, de Castillejo, de h. 1522, ver Cacho (2005) y Perinán y Reyes (2012). Sobre el manuscrito de Celestina en el Palacio Real, Faulhaber (1990) y Blecua (2010). 12. (Ferreres 1975: 34). La edición del texto por Rafael Ferreres se hizo a partir de la prínceps de las obras de Fernández de Heredia (Valencia, 1562), sin tener en cuenta este manuscrito, que presenta interesantes variaciones respecto, por ejemplo, a la extensión, localización y carácter de las didascalias. 
para la copia de la obra teatral, ofreciendo una copia limpia y visualmente atractiva, quizá pensada para la lectura de la corte o el traslado a la imprenta.

El carácter de este manuscrito, limpio, ordenado y rubricado a la manera cancioneril, contrasta con otro interesantísimo, que contiene la Comedia a lo pastoril para la noche de Navidad (Comedia, s.a.), borrador con tachaduras, pero claramente pensado no para la lectura, sino para la representación, como demuestra el que los últimos dos folios contengan dos documentos de gran interés, que atienden a circunstancias específicas para ordenar la función. En primer lugar, la posibilidad de reutilización de los actores que intervengan en la representación doblando papeles:
el q[ue] hiciere el hombre podrá ser Joseph
el q[ue] fuere deseo podrá ser un pastor
el que fuere la divinidad podrá ser nra señora
el que fuere la justicia podrá hazer un pastor
el que fuere la misericordia podrá hazer otro pastor
el que fuere la paz podrá hazer un ángel
el que fuere la v[er]dad podrá hazer otro ángel
el amor
el Verbo Eterno por si (Comedia, s. a: fol. 13v).

El segundo contiene un listado con detalles del vestuario y su colorido y el atrezo que debe usarse en la representación, así como algunas indicaciones del aspecto físico del actor a quien se adjudique determinado papel: «ha de ser muy hermoso y pequeńo». Este listado nos permite imaginar el impacto visual, casi pictórico, de la representación: ${ }^{14}$

Los vestidos. el hombre. unos vestidos q[ue] ni bien sean de hombre ni bien de mujer. muy viejo barba blanca tocados en la cabeza.

el deseo. vestido de verde como pastor

la divinidad muy rica mente vestida una corona en la cabeza y un ramo de laurel en la mano

la justicia vestida de azul con una espada desembainada en la mano.

la paz. vestida de morado con su cayado

la misericordia. de colorado con un ramo de oliva

la v[er]dad. de blanco y una Regla en la mano

El Verbo Eterno de colorado no bien como hombre ni bien como mujer muy $\mathrm{g}$ [a] rrido como luchador en la mano un cayado en la cabeza diadema el amor vestido de morado pintados algunos coraçones. en la cabeza una guirnalda. a de ser muy hermoso. y peq[ue]ño.

14. Sobre el impacto visual del vestuario en la fiesta cortesana y la formación del gusto teatral en el renacimiento ver Warburg, 2005: 306. El simbolismo de los colores funciona como códi-

go teológico en la pintura del final de la Edad media y se extiende a la renacentista, como explica Baxandall (2000: 108). 
el ángel ya se sabe con alba y estola y diadema

nra señora como de camino

Joseph. como biexo con taio y de camino

los pastores como tales

Y finalmente el orden de los pasajes cantados:

el primer cantar cantarán el hom[bre] y el deseo

2. el deseo

3. la divinidad y la justi[ci]a

4o la just [ici]a

5. la paz

6. la verdad

7. la misericordia

8 la misericordia

9 el Verbo Eterno

10. el hombre

11. el amor

12 el amor

13 el amor

14 los pastores (Comedia, s.a. fol. 14r). ${ }^{15}$

No obstante estos dos ejemplos, la escasez de manuscritos teatrales de este primer teatro del siglo XVI no permite excesivas indagaciones sobre su naturaleza y su uso (autógrafo, original de imprenta, copia encargada para lectura privada, copia de compañía para actores, etc.), como se ha intentado hacer para el teatro del siglo XVII. Mayor riqueza ofrecen los impresos.

Junto con la mencionada edición de Enzina (y la de otros Cancioneros, tal el de Pedro Manuel de Urrea), ${ }^{16}$ que instituye el modo de transmisión impresa del teatro del primer renacimiento español, debemos considerar la difusión temprana de piezas teatrales en pliegos sueltos. Para Pérez Priego, estos pliegos pudieron atender a diferentes realidades de representación, por lo que cada edición suelta no denunciaría sino una realización textual única e irrepetible de la pieza dramática, que se manifiesta en la incorporación de villancicos finales o de introitos iniciales, presentes en unos pliegos y ausentes en otros impresos (Pérez Priego, 1998: 159). La edición de las Farsas y églogas de Lucas Fernández en Salamanca 1514, presenta una distribución en pliegos, perceptible a través de las signaturas del impreso, que permitiría sospechar la formación del volumen a partir de piezas sueltas individuales, ya que cada pieza comienza y termina

15. El editor de esta Comedia (Crawford, 1911) transcribe estos folios finales, pero no concede en su estudio relevancia a la información que proporcionaban, más preocupado de aspectos del contenido de la obra.

16. Hay edición reciente de María Isabel Toro Pascua, (Urrea 2012); el tomo III contiene las églogas. 
cuaderno. La difusión de las obras de Torres Naharro en sueltas quizá provocó su deseo de imprimir sus obras recopiladas en la Propalladia cuando se traslada a Nápoles en $1517 . .^{17}$

La consideración de estos modos de transmisión textual, compartidos por el teatro con otros géneros, nos permite identificar una característica de este nuestro primer teatro impreso: la falta en la tradición espańola de un formato impreso o manuscrito específico para recoger el teatro, al estilo del formato agenda que recuerda Pedro Cátedra (2005: 12) era el preferido en Francia por su manejabilidad por los representantes $;{ }^{18}$ de esta forma, los autos, églogas o farsas se imprimen como piezas poéticas, bien en los cancioneros o bien en las sueltas, adoptando en muchas ocasiones modos característicos de géneros no dramáticos, de manera que los impresos teatrales carecen de marcas específicas que orienten al lector en la oralidad implícita en el texto o en sus mecanismos dialogales.

Un caso muy representativo de esta disfunción del impreso teatral es el de las ediciones de La Celestina. Llamaba la atención sobre ello el corrector de la impresión veneciana de la obra, Alonso de Ulloa, quien cuando saca al mercado su edición en 1553, al dedicarla a su destinatario, Bartolomé de Vargas, Capellán del Emperador valoraba su producto con razonamiento que vale la pena citar por extenso:

la qual Tragicomedia, después que del auctor la heredamos, no solamente se ha imprimido más y más vezes en la lengua Castellana, en Hespaña y fuera d'ella, mas aun también en la Thoscana y otras ha sido traduzida; y últimamente viniendo a mis manos, y aun impressa ya en tres partes en Romance, la lehi muy de propósito más vezes, y al cabo de haverla visto y notado bien; hallé, que ni en Hespaña, ni en Flandes, ni en otras partes no la habían dado al mundo como convenía, porque la vi oppressa de dos faltas muy principales, la una mal corregida y sin ninguna ortographía (que es por cierto falta muy grande en un libro) y la otra, siendo comedia como lo es, que la hayan impresso no como comedia, sino como historia, o otra composición simile, prosiguiendo siempre desde el principio del Aucto hasta el fin sin poner en la margen los interlocutores, que de passo en passo uan hablando, que a mi ver es un importante error en el tal libro, y se le ha hecho gran sin razón, pues veemos que las comedias de Terencio y de Plauto

17. Sobre las sueltas de las obras de Torres $\mathrm{Na}$ harro, ver Gillet, 1943: 79-94. La difusión en pliegos sueltos o en cuadernos desgajados de un impreso mayor es una forma común de difusión de las piezas teatrales, como se comprueba en el hato de Gaspar de Oropesa donde se inventarían «los autos que mi marido, Gaspar de Oropesa, que aya gloria, dejóm: 19 cuadernos de obras, 36 autos y comedias en un emboltorio otras 36 obras en un emboltorio de marquilla», (Cátedra, 2006: 503).
18. El formato agenda evoca un uso profesional del manuscrito teatral (Hasenohr, 1990: 340b). No tenemos en España - hasta donde sé- nada parecido a los rolets de théatre franceses en los que los actores estudiarían sus papeles (roles), en «rollos» (roles) de pergamino o papel con anotaciones de actuación (Lalou, 1991). Los «papeles de actor» que estudia Vaccari eran doblados hasta alcanzar el formato en octavo que permitía guardarlos en un bolsillo (Vaccari 2006: 21). Para la tradición inglesa, ver Werstine (2013). 
y d'otros han sido y están impressas con muy gentil orden: es a saber, que cada persona que en la comedia va hablando, tiene su nombre sacado en la margen, y donde acaba el uno su parlamento, no prosigue allí luego el otro, sino comiença nuevo renglón con el nombre a fuera (dado que aquellas sean Latinas, y que por los auctores d'ellas han sido escriptas en verso) y esto mismo han usado y usan los Ytalianos en las suyas. Lo primero que tengo dicho puedese atribuir a la poca diligencia que se usó en la impresión, mas de lo segundo es de maravillar, y me maravillo infinito de tantos como hasta aquí l'han hecho imprimir, que no hayan caydo en ello, pues que se vee ser evidente error. Por lo qual, ya que nadie no ha mirado en esto, o si lo ha no ha, puesto remedio, me atreví yo a tomar la mano y ser el primero que en tal guisa la hiziesse estampar, creyendo (como creo) hazer grato servicio a mi nación ; y ansí hallándome en Venecia la corregí en todo lo que convenía (no digo que la haya mudado ningún vocablo antiguo, que todos se los he dexado, como los compuso el auctor, juzgando ser temeridad haciendo al contrario), sino que la he emmendado de los errores de la estampa, y con summa diligencia impresso a manera de comedia, a fin que de todos fuesse bien lehída, y entendida como conviene (Rojas, 1553: fol. 2v-3r, cursiva mía).

En la misma portada de esa edición (Venecia, Gabriel Giolito de Ferraris y sus hermanos, 1553) se anunciaba como reclamo el haber sido «impresa en guisa hasta aquí nunca vista»; y en efecto, se dispone el texto "teatralmente», con el listado inicial de "INTERLOCUTORES DE LA TRAGICOMEDIA» (Rojas, 1553: fol. 9v), en lista que identifica el nombre del personaje y su rol en la obra; el texto de la obra va en cursiva sangrado con relación a la identificación de los interlocutores, cuyas iniciales se sitúan al margen. ${ }^{19}$

Por otra parte, conocemos el disgusto del autor (o del corrector) por la labor de los impresores a la hora de poner en página su texto, tratándolo como un texto narrativo y no dramático y ańadiendo argumentos en prosa donde no eran necesarios, más allá del introductorio claramente teatral:

Que aun los impresores han dado sus punturas poniendo rúbricas o sumarios al principio de cada acto, narrando en breve lo que dentro contenía; una cosa bien escusada según lo que los antiguos escritores usaron. (Rojas, 2000: 20). ${ }^{20}$

19. No es mi propósito discutir en este trabajo la naturaleza genérica de La Celestina; asumo y comparto los planteamientos y análisis detallado de la obra como teatro que desarrolla Emilio de Miguel (Miguel Martínez, 1996: 124-199, y 2009) y remito a la bibliografía que allí se cita sobre uno de los temas más debatidos de la crítica celestinesca. Aporta reflexiones muy interesantes sobre la ubicación de La Celestina en la tradición dramática del xv y la posible difusión en Castilla de la misma, el trabajo de Ottavio di Camillo (2005).

20. «Se diría que esta discrepancia entre los im- presores y Rojas refleja una lectura de La Celestina como obra narrativa (...) y otra lectura, la del propio autor, dominada por los modelos dramáticos» (Rojas, 2000: 511). Una reflexión brillante sobre el problema ecdótico y tipobibliográfico de los argumentos y las dramatis personae de La Celestina es el de Gonzalo Pontón (2012). El argumento inicial - no los posteriores- como forma de iniciar la representación ha sido explicado por Stone Peters (2000: 167-169). Emilio de Miguel (2013:198-199 ) afirma: «Tengo para mí que en el caso de La Celestina se aúnan usos tardomedievales con tradición latina 
Es quizá esa forma de plasmación impresa de La Celestina — de la que se quejaba Rojas y que trata de remediar Alonso de Ulloa- la que contribuyó también a la recepción de la obra por parte de los lectores del xvi fuera del marco de la tradición dramática, como perteneciente a una tradición narrativa, tal y como explicó con perspicacia Ottavio DiCamillo, no solo por la «escasa familiaridad o desconocimiento de las experimentaciones escenográficas y representaciones teatrales» (DiCamillo, 2005:64), sino también porque el formato impreso en que se ofreció la obra empujaba a esta «institucionalización literaria»: «Siendo comedia como es [...] la hayan impresso no como comedia, sino como historia", según acabamos de ver se lamentaba el editor veneciano de la obra.

La mención de los «antiguos escritores» de Rojas y de las ediciones de Terencio y Plauto por parte del editor Alonso de Ulloa en la edición veneciana de 1553, remite a un espacio de referencia imprescindible en la construcción de los modos de impresión del texto teatral para el primer Renacimiento, y que sin duda suponen un aporte que debe ser tenido en cuenta. ${ }^{21}$ El texto dramático de Terencio fue con frecuencia editado con comentarios que en la puesta en página lo rodeaban, reproduciendo la tradición de las glosas bíblicas y de los textos clásicos comentados; pero aparece precedido de los fabulae interlocutores, primera de las didascalias explícitas para el lector, y con especificación mediante epígrafes en la cabecera del impreso de la estructura externa de la obra. Además, incorporan con frecuencia interesantes grabados, de los cuales se ha podido suponer que cumplen una función no meramente decorativa, sino ilustradora de rasgos escénicos de representaciones en Ferrara o Roma. ${ }^{22}$

y así el propio Argumento de toda la obra es en alto grado una imitación de esos prólogos que Rojas había leído en el teatro latino. Cuando, a continuación, critica frontalmente la errada inclusión de argumentos parciales al comienzo de cada acto, estaba reprochando al impresor no haber entendido en absoluto la función plenamente teatral del Argumento de toda la obra. Imaginemos que incluso hoy, cuando con tanta facilidad se hace saber al espectador que va a comenzar la representación - oscurecimiento de la sala, avisos por megafonía-, una hipotética representación de La Celestina se iniciara con el recitado del Argumento de toda la obra, y que el actor que lo realizara, al tiempo que habla, fuese señalando de forma inequívoca a los distintos personajes que nombra (...) No sólo se está consiguiendo una presentación muy eficaz y práctica de los personajes principales y del meollo del argumento, sino que hasta parecería que se está dando paso al inicio de la representación, cuando quien esté recitando ese Argumento de toda la obra, invitara con algún gesto a retirarse de escena al resto de personajes para focalizar la atención de los espectadores en los dos que habrán de poner en marcha la acción».

21. Gilman (1954/1955: 71-72) remite a conversación con Ma Rosa Lida quien le apuntó los modelos de las ediciones de Plauto y Terencio como referencia a esos "antiguos escritores». Para Howard-Hill, el modelo de las impresiones de Terencio, Plauto y Séneca a partir de 1470 fue determinante de una forma de imprimir el teatro en Inglaterra (Howard Hill,1990: 112 y 130). En la biblioteca de libros en romance que recoge el inventario de bienes de Rojas a su fallecimiento en 1541 aparece reflejado "Anfitrión", probablemente la traducción de López de Villalobos (Infantes, 2010: 149).

22. Puede verse como ejemplo la edición de Terencio, Venecia, 1499. Aunque se trata de una edición italiana, sirve de referencia para España, dado el intenso tráfico de libros entre los dos países y el hecho de que las prensas ex- 
También la 'mise en page' de la traducción del Amphytrion de Plauto, publicada en Alcalá en 1517, del doctor Villalobos (López de Villalobos, 1550) dispone el texto impreso en letra gótica en doble columna; las glosas, en gótica o redonda - según las ediciones-, de cuerpo menor a los márgenes, lo que supone un esfuerzo de diferenciación para el lector entre el texto dramático y su comentario a través de los tipos de imprenta. Cuando las glosas desbordan el texto, este queda en el centro, rodeado de glosa, como ocurría, por ejemplo, con los textos bíblicos glosados y con los jurídicos. Se identifican los personajes con nombre completo al comienzo de cada escena (que se antecede de una pequeña glosa de situación); los parlamentos a renglón seguido solo con iniciales (alternando con abreviaturas más largas o el nombre completo del interlocutor, es de imaginar que por problemas del oficial de la imprenta en el ajuste de la cuenta del original).

Que estas ediciones están pensadas para la lectura y no para la representación, lo deja claro López de Villalobos en el prólogo a su traducción:

Aquí se vuelve de latín en romance la primera comedia del Plauto, cuyo nombre es Amphytrion. La trasladación es fielmente hecha sin añadir ni quitar, salvo el prólogo que el poeta haze en nombre de Mercurio y sus argumentos, que esto era bueno para representar la comedia en público y hazer farsa della, porque los miradores entendiesen bien los passos todos. Aquí no se pone aquello, porque sería cosa desabrida y sin gusto. Bastan los argumentos que yo pongo, porque dan mejor a entender la comedia, y son más sabrosos para los leyentes (Lopez de Villalobos, 1550, fol. XLVIIr Prohemio)

Frente a los «miradores», para quienes está pensado el prólogo (cuya imitación influirá en los introitos de Enzina y Torres Naharro), los «leyentes» necesitan otro tipo de material que favorezca el «mejor entender la comedia». Sin embargo, en contraste con esta conciencia, la traducción de Joan de Timoneda en 1559 apela en su prólogo al público para que se disponga a «oýr, ver representar la primera

tranjeras satisficieron la demanda hispana de comedias latinas, como señala Edwin J. Webber, (1957/1958: 34; ver también Webber 1956). Estos textos editados en Italia debieron servir como referencia para las actuaciones estudiantiles que observaban los estatutos de la Universidad de Salamanca: «Item de cada collegio cada año se representará una comedia de Plauto o Terencio o tragicomedia (...) y el regente que mejor hiziere y representare las dichas comedias o tragedias se le den seis ducados». Estatutos hechos en la Universidad de Salamanca, (1538), Título LXI «De los colegios de Gramática y de lo que en ellos se ha de guardar», fol. Eiiiro. Sobre el teatro en la Universidad de Salamanca ver ahora Ma Jesús Framiñán de Miguel, (2011: vol. I, pp.
271-469), pero también Devid Paolini (2011). La importación de libros teatrales de Italia para la Universidad la documenta Vicente Bécares, en la obligación notarial que publica, de 17 de abril de 1532 acerca de "Los libros griegos y ebraycos que havemos de hazer traer de molde de Venetia para la Universidad de Salamanca»; entre ellos: Aristófanes, Comoediae novem (con los escolios de Marco Musuro), Venecia, Aldo, 1498; Sófocles, Tragaediae septem cum commentariis, Venecia: Aldo, 1502, Esquilo, Tragoediae, Venecia: Aldo, 1518, Eurípides, Trageoediae septendecim, Venecia: Aldo, 1503, (Bécares, 1998: 105-109). Sobre las ediciones españolas en Italia y su difusión ver Norton, (1966; 136-137) y Misiti (1992). 
comedia de Plauto». La diversa conciencia del médico López de Villalobos y del dramaturgo Timoneda entre escena y lectura individual es muy esclarecedora del cruce que se produce en el primer Renacimiento español entre teatro e imprenta. ${ }^{23}$

Las ediciones tempranas de los clásicos griegos y romanos eran ediciones para la lectura, y su prestigio pesó, sin duda, en la institución del modelo de impresión teatral. ${ }^{24} \mathrm{El}$ formato impreso parece determinar el modo de lectura individual y silenciosa, en ese proceso de consumación institucional del monumento literario. Pero la lectura silenciosa individual no es la prevista en exclusiva para el teatro impreso. Lo explica bien la Lozana andaluza (1528), cuando despide a uno de sus amigos, Silvano, y le pide que vuelva:

Porque quiero que me leáis, vos que tenéis gracia, las coplas de Fajardo y la comedia Tinalaria y a Celestina, que huelgo de oír leer estas cosas muncho.

SILVANO: ¿Tiénela Vuestra Merced en casa?

LOZANA: Seńor, velda aquí, mas no me la leen a mi modo, como haréis vos. Y traé vuestra vihuela y sonaremos mi pandero ${ }^{25}$.

$\mathrm{Al}$ margen de posibles sentidos eróticos de la vihuela del mozo y el pandero de la lozana joven con que ambos van a hacer música — y otras armonías - tras la lectura, aquí se construye un modo de lectura privada, pero dramatizada, por un actor y músico (ambas funciones solían ir juntas en las fiestas cortesanas), que es en la que el teatro impreso alcanza su sentido y el oyente accede de manera más gustosa y eficaz al texto teatral, cuando alguien con maña le lee el texto «a su modo». Era la difusión prevista por el autor del prólogo de la Tragicomedia de Calisto y Melibea: "Así que cuando diez personas se juntaren a oír esta comedia..., como suele acaecer...».

Las meritorias ediciones impresas de textos teatrales no siempre eran conscientes de las limitaciones que suponía la invitación a la lectura silenciosa del texto, que va implícita a su fijación en letras de molde, eso que se ha llamado

23. Ver Ma J. Ibáñez Pérez (1990). María Cristina Quintero considera que en comparación con la traducción de López de Villalobos, la versión impresa por Timoneda era una versión para representar ante el público, con aguda conciencia de las necesidades dramáticas (Quintero, 1990). Las obras dramáticas de Pérez de Oliva se imprimen como prosa, insertando los parlamentos distintos a línea seguida, al menos en la edición que he visto (Pérez de Oliva,1586).

24. "The early editions of Plautus, Seneca and Terence were primarily reading texts» (HowardHill, 1990: 135). De Séneca se puede ver, por ejemplo, la edición de las Tragedias en París, 1514, con el trabajo filológico de Erasmo, entre otros y la edición del texto rodeado de los comentarios de Badio Ascensio, Bernardino Marmita y Daniele Gaietano Cremonense (Séneca, 1514).

25. La lozana andaluza, mamotreto XLVII, (Delicado 2006: 236). Así interpreta también el texto de La Celestina el anónimo lector del siglo xvi de La Celestina comentada (Corfis, 1993). En ámbito inglés, Chambers ofrece el ejemplo del interludio The Life and Repentence of Mary Magdalene de Lewis Wager, en 1566, en cuya portada leemos: "A new Enterlude, neuer before this tyme imprinted (...) very delectable for those which shall heare or reade the same». (Chambers, 1951,Vol. iii: 503). 
«el sacrificio del teatro en el altar de la publicación». ${ }^{26}$ Los impresos suponen siempre un falseamiento de la naturaleza oral "performativa» con que ha sido concebido el texto teatral. Lo sabía bien Lope, que en la dedicatoria de $\mathrm{La}$ Campana de Aragón escribe:

La fuerza de las historias representada es tanto mayor que leída, cuanta diferencia se advierte de la verdad a la pintura y del original al retrato: porque en un cuadro están las figuras mudas, y en una sola acción las personas, y en la Comedia hablando y discurriendo, y en diversos afectos por instantes (...). Nadie podrá negar que las famosas hazañas, o sentencias referidas al vivo con sus personas, no sean de grande efeto para renovar la fama, desde los Teatros, a las memorias de las gentes: donde los libros lo hacen con menos fuerza, y más dificultad y espacio (Vega, 1623, Dedicatoria).

La lectura del texto impreso debería permitir al lector reconstruir o descifrar los modos de oralidad: canto, voz alta o baja, gestualidad implícita en la comunicación oral. Los autores son conscientes de la necesidad de oralidad incluso en la lectura, como explica bien el corrector de la impresión Alonso de Proaza al lector de La Celestina:

\author{
DICE EL MODO QUE SE HA DE TENER LEYENDO ESTA TRAGI- \\ COMEDIA \\ Si amas y quieres a mucha atención \\ leyendo a Calisto mover los oyentes, \\ cumple que sepas hablar entre dientes \\ a veces con gozo, esperanza y pasión; \\ a veces airado, con gran turbación. \\ Finge leyendo mil artes y modos, \\ pregunta y responde por boca de todos, \\ llorando y riendo en tiempo y sazón. (Rojas 2006: 276). ${ }^{27}$
}

El texto teatral lleva implícita la huella de la oralidad y los códigos que para la comunicación del texto en la época pueden ser claros, pero que han perdido para nosotros su presencia (Chartier, 2000: 249). Como la referencia a una canción que se ha de cantar en escena, de la que se menciona un verso inicial, pero cuya melodía desconocemos (nosotros, pero no los lectores/oyentes para los que se destinó el texto).

En este sentido sería necesario un estudio pormenorizado del aspecto oral implicado en la puntuación en los textos teatrales para buscar un código impreso

26. Título del artículo de Abby E. Zanger, (1988), cit. en Chartier (1999: 26). Sobre la lectura en voz alta de todo tipo de textos en el siglo XVI ver Stone Jones, 2000: 93-94.
27. Para Shergold (1967: 170 n. 3) «Proaza's concluding verses seem to imply both a 'lector' and an audience, and also to expect from this reader a fair amount of 'acting skill». Ver Lida de Malkiel (1984) y Corfis (1993). 
explícito de oralidad que mostrara al lector del teatro las vías de reconstrucción de ese modo comunicativo previsto por el texto y le permitiera incorporar a la lectura el proceso de interpretación. ${ }^{28}$ Poco más podemos añadir a lo apuntado por el maestro Alberto Blecua (2012) a propósito de la «no puntuación» de los textos dramáticos. Tras constatar el «extrańo fenómeno» de la ausencia de puntuación en los autógrafos de los poetas dramáticos del XVII, de Lope a Cañizares, lo interpreta como exigencia de los autores de comedias, que desean textos sin puntuar para poder marcar el ritmo de la entonación y de la cadencia del verso; por lo tanto, vincula el fenómeno a la aparición de los corrales y de las compañías profesionales. La escasez de los manuscritos originales de piezas del XVI nos deja desasistidos al respecto, por lo que debemos remitirnos a los impresos que los transmiten. La costumbre de controlar la puntuación y la ortografía de los textos manuscritos en las imprentas, cada una de las cuales pudo tener su criterio (o incluso dentro del mismo taller, criterios distintos de distintos componedores), deja ese código de lectura al arbitrio de los oficiales encargados de la composición del texto a partir de los originales manuscritos, de los que tampoco tenemos noticia. No hay tampoco en español estudios comparables a los que cita Chartier (1999) sobre el teatro de Molière o de Shakespeare. ${ }^{29}$

Veamos un par de ejemplos.

La princeps de La Celestina, Burgos 1499 comienza de la siguiente manera:

Enesto veo Melibea la grandeza de dios. Me. en que calisto. Ca. en dar poder a natura que de tâ perfeta hermosura te dotasse : e fazer a mi îmerito tanta merced q ver te alcâçasse : e en tâ côveniête lugar q mi secreto dolor manifestar te pudiesse. sin duda encôparablemente es mayor tal galardón q el servicio : sacrificio : deuociô e obras pias que por este lugar alcançar têgo yo a dios ofrescido. Ni otro poder mi volûtad humana puede côplir. quien vido enesta vida cuerpo glorificado de ningún hôbre como agora

28. La Ortographía de Alejo Vanegas reconoce a las claras ese componente oral de la puntuación cuando escribe: «Para saber la punctuación de que usan los latinos en la oración, es necesario saber que en el razonamiento que va pendiente solemos usar de ciertos entrevalos y pausas, así para que descanse el que habla, como para que perciba y entienda bien el que oye (...) Digo pues que la punctuación haze que descanse el que habla, y perciba bien el que oye, y entienda el que lee», (Vanegas, 1531: fol. d5v). La posibilidad de que la puntuación incorpore el proceso de interpretación oral del texto escrito es señalada por Parkes (1992: 1-2) y aplicada a la predicación y al rezo en impresos litúrgicos (Parkes, 1992: 76-80).

29. No puede aplicarse al caso español lo escrito por Parkes: «In sixteenth-century editions of classical plays layout and punctuation (...) preserved the integrity of the verse as dramatic poetry. However most contemporary plays were written for performance rather than Reading. The printed texts of these plays reflect the circumstances for which they were originaly written to the extent that punctuation of the verse signals patterns of elocutionary units in different registers of spoken discourse» (Parkes, 1992: 111). La puntuación de La Celestina que estudia Fidel Sebastián Mediavilla (2003), no atiende a la funcionalidad prosódica teatral, es decir, enfatizar palabras, introducir pausas, apoyar la gestualidad, etc. Parkes (1992: 56) se refiere, por ejemplo, al uso en textos dramáticos de signos de suspensión (un guion simple o tres o más puntos) cuando se interrumpe un parlamento. 
el mio. Por cierto los gloriosos sanctos q se deleytâ en la visión diuina no gozan mas q yo agora en el acatamiêto tuyo. Mas o triste que enesto deferimos : que ellos puramête se glorifican sin temor de caer de tal bienauêturâça : e yo misto me alegro cô recelo del esquiuo tormêto q tu absencia me ha de causar. Me. por grand premio tienes esto calisto. Ca. tengo lo por tanto... (Rojas, 1499: fols. 1v-2r)

Llama la atención la ausencia de marcas de entonación interrogativa o exclamativa; las pausas breves señaladas convencionalmente con comma (:) y las largas con el colum (.). ${ }^{30} \mathrm{La}$ integración de las marcas de personaje en la línea de texto resta funcionalidad a la didascalia explícita, así como la no utilización de cursivas u otros diferentes tipos de letra. En conjunto, la información sobre la naturaleza escénica del texto para el lector no es muy abundante en el impreso. ${ }^{31}$

La edición de Cromberger en Sevilla, (Rojas, 1502) ${ }^{32}$ señala entre paréntesis las iniciales de los personajes que intervienen en los parlamentos, que quedan así más identificados visualmente para el lector e incorpora interrogaciones (sólo al final del periodo, claro). Se explica que en los últimos versos, se exprese ahora el orgullo del editor cuidadoso, que se ha preocupado de la corrección textual y ha avanzado modos de puntuación:

quando este muy dulce y breve tratado después de revisto y bien corregido, con gran vigilancia puntado y leido

fue en Seuilla impreso acabado

(Rojas 1502: fol. 82, sub. mío). ${ }^{33}$

30. Es el modelo de Nebrija: «Con punto (.) y dos puntos (:) exclusivamente se puntúan las Introductiones, la Gramática (1492) o los prólogos del Diccionario latino-español (1492) y del Vocabulario español latino (¿1495?). Y ya en el siglo Xvi el De vi ac potestate litterarum (1503), impreso con letra redonda y las Reglas de ortographía (1517)» (Santiago, 1996:279).

31. Fidel Sebastián, (2010) hace un estudio comparativo de la puntuación en el Manuscrito de Palacio $(M p)$ y las ediciones antiguas de $L a$ Celestina, destacando que la de Burgos 1499 y el manuscrito coinciden en la ausencia del signo de interrogación. "El sistema de puntuación de $M p$ consta tan solo de dos signos de puntuación (el punto y la barra) y carece del absolutamente necesario interrogante. No resulta insólito para un manuscrito sea autógrafo o apógrafo. Sí lo es, en cambio, encontrarlo en un impreso, la edición burgalesa de la comedia, que se atiene también a dos solos signos de puntuación: en este caso el punto y los dos puntos», (Sebastián, 2010: 526).
32. El ejemplar que uso, de la Biblioteca $\mathrm{Na}$ cional de Buenos Aires, digitalizado en la Biblioteca Cervantes Virtual, se cataloga con la indicación falsa Sevilla, Cromberger 1502, pero no se identifica en la página web a cuál de las ediciones posteriores corresponde. Agradezco a la profa. Georgina Olivetto la referencia a su trabajo (1998) y a la nota de Charles B. Faulhaber (1992) donde se documenta que el ejemplar bonaerense corresponde en realidad a la edición de Roma, Marcellus Silber, c.1516. Puede verse digitalizado el ejemplar de la Boston Public Library, http://archive.org/details/tragicomediadeca00roja (consulta el 19 de febrero de 2012). No es mi intención, en cualquier caso, entrar en el «laberinto cronológico» de las ediciones de Celestina (Infantes, 2010: 11).

33. Para McPheeters (1956: 15 y 21) la labor de corrección de la puntuación correspondería a Alonso de Proaza. El hecho de que se refiera a la obra como «tratado» es para Infantes señal inequívoca de que es obra de un profesional de la edición (Infantes, 2010: 51). 
Los mismos recursos de disposición de la página se comprueban en la edición de Juan Jofre, Valencia, 1514 (aunque el último verso citado lee «fue en Salamanca impreso acabado", Infantes, 2010: 88).

Si comparamos estas ediciones con la primera edición italiana, en Roma, 1506, traducida por Alfonso Ordóńez, comprobamos en esta una mayor atención a la distinción de los interlocutores, destacados en mayúsculas y entre punctus (+_+), y un uso de la puntuación que, además de incorporar los signos interrogativos, parece atento a las pausas enfáticas de dicción, con el uso de comma y, sobre todo, con la incorporación de la vírgula inclinada (/) en forma de inciso expresivo (evidente, por ejemplo, en la puntuación de la interjección exclamativa: «conspecto $+\mathrm{Ma}$ o/ misero»): ${ }^{34}$

\section{Calisto+}

In questo uedo Melibea la grâdeza di Dio + $\mathrm{ME}+$ in che Calisto? CAL+ per hauer data potentia a la natura che de cosi pecta belleza te / dotasse : e fare a me indegno de tanta gratia che uedere te potesse: $\mathrm{e}$ in cosi conueniente luogo chel mio secreto dolore te potessi manifestare: senza dubio incomparabile e maggior tal gratia : chel servitio : sacrificio : deuotioni : et opere pie : che per arriuare a questo luogo / ho / a Dio offerto chi uidi mai in questa uita corpo glorificato si como /e/ adesso il mio? per certo gli gloriosi Sancti : che si dilectano nella diuision diuina : non godeno piu che fo io adesso nel tuo conspecto $+\mathrm{Ma}$ o/ misero me che solo in questo semo differenti : che loro puramente se glorificano : senza timore di perderé quella: et io misto me ralegro con timore del futuro tormento : che tua absentia de deue causare $+\mathrm{ME}+$ per cosi gran gratia / hau tu questa Calisto? + CA+ io lo per tanto in uerita... (Rojas, 1506: B8r y v).

No parece haber en ninguna de estas ediciones antiguas de Celestina (como en ninguno de los otros impresos teatrales que he visto) un uso expresivo de las mayúsculas, o de las cursivas, para visibilizar palabras importantes al ojo lector y mostrar la necesidad de enfatizar su lectura en voz alta. ${ }^{35}$ Es decir, eso que Chartier ha llamado «tipografía expresiva» para referirse a los mecanismos que recogen la oralidad del impreso teatral en otras tradiciones (Chartier, 1999: 21 y $2000: 254) .{ }^{36}$ No creo que podamos interpretar de esta forma — por su excep-

34. Alejo Vanegas, afirmaba que la vírgula «sirve de comma quando la sentencia es muy imperfecta porque no ay verbo y es necesario tomar un huelgo insensible que no sea tan behemente como el de la coma», (Vanegas, 1531: fol. d6v). Sobre la vírgula inclinada en impresos del siglo Xvi ver además Santiago (1996: 279 n. 35 y 281 y 1998: 250-253) y Sebastián (2007: 15-16). Parkes apunta el uso de la virgula suspensiva para marcar unidades declamatorias (Parkes, 1992: 78). Tomo el nombre punctus para el signo $+\mathrm{de}$ Parkes (1992: 306).
35. Sí se utilizan cursivas - a nombre completo o en abreviatura, según las necesidades del cajista- para destacar el nombre de los interlocutores que intervienen en el diálogo, frente a la redonda del texto del diálogo en la edición de La Celestina en Salamanca, 1590 (Rojas, 1590).

36. Me pregunto si la normalización ortográfica de los signos de puntuación con que se llevan a cabo las ediciones modernas no acaban con posibles puntos expresivos, sin tener en cuenta la naturaleza de la lectura — silenciosa o en voz alta- prevista para el texto y el carácter normativo 
cionalidad- las mayúsculas con que se imprimen dos breves pasajes en parlamentos de la Celestina veneciana de 1553. En el final del aucto XIX se imprime así el parlamento de Melibea:

Me. Oyes lo que aquellos moços van fablando? Oyes sus tristes cantares? Rezando llevan con reposo mi bien todo, muerta llevan mi alegría, no es tiempo de yo vivir ; cómo no gozé más del gozo? cómo tuve en tan poco la gloria que entre mis manos tuve? O INGRATOS mortales jamás conocéys vuestros bienes sino quando dellos carecéis (Rojas, 1553: fol. 141v).

En el monólogo final de Pleberio, aucto XXI, se imprime así esta frase: «O MUNDO, Mundo, muchos de ti dixeron» (Rojas, 1553: fol. 147v).

En ambos pasajes la mayúscula empleada por el tipógrafo coincide con dos casos de inicio de exclamación (por supuesto, sin puntuación que lo indique). La posibilidad de interpretarlo como un uso tipográfico expresivo es tentadora. Pero, debemos pensar que, a pesar de la voluntad del editor, Alonso de Ulloa, de editar la obra como teatro, este uso de las mayúsculas no trata seguramente de indicarle al lector la oralidad del parlamento, sino que responde a error del cajista, que interpreta como refranes ambas frases y comienza a componerlas con tipos de mayúscula, ya que, en efecto, le edición destaca de esta forma (mediante mayúsculas) todos los casos del amplio refranero empleado en numerosos lugares por los interlocutores. ${ }^{37}$

La plasmación tipográfica en la primera edición de 1514 de las Farsas y églogas al modo pastoril, de Lucas Fernández en Salamanca, a cargo de Lorenzo de Liondedei nos deja igualmente bastante desasistidos respecto a los indicios gráficos de oralidad y otras ayudas. Más allá de las iniciales que identifican los parlamentos de los personajes, sangrados ahora a la izquierda con relación a la columna de texto, como ocurría en las églogas el Cancionero de Enzina, se prescinde casi por completo de puntos. ${ }^{38}$ Solamente cuando el verso se parte

de la misma. Quizá habría que preguntarse si los puntos esconden criterios de otra naturaleza que la meramente prosódica o de estructura lógica de la frase, o, en el impreso, si responden a criterios puramente materiales de cuenta del original, e incorporan en los textos dramáticos unidades de pronunciación, como las que consigna Parkes (1992: 112) en la puntuación de un fragmento de la edición en el first folio de The Winter's Tale. Sobre las normas prácticas de puntuación ver Parkes (1992: 87-92) y para el caso español Sebastián (2007:65-73).

37. Este uso de las mayúsculas en la edición de la Celestina en Venecia en 1553 parece responder a la utilización de la obra como vehículo para el conocimiento de la lengua espańola, como se comprueba en el hecho de que la pieza se imprima junto con dos piezas que complementan esa intención didáctica, un manual de pronunciación y un vocabulario: INTRODUTIONE DEL SIGNOR ALPHONSO DI VGLIOA, NELLA QUALE SINSEGNA PRONVNCIARE LA LINGVA SPAGNOLA,CON VNA ESPOSITIONE DA LVI FATTA Nella Italiana, di parecchi vocaboli Hispagnuoli difficili, contenuti quasi tutti nella Tragicomedia di Calisto e Melibea $o$ Celestina.

38. El manuscrito de la Farça a manera de visita de las damas (Fernández de Heredia, 1524), descrito anteriormente y que reproduce los modelos cancioneriles, carece igualmente por completo de todo tipo de puntuación, salvo que conside- 
en dos parlamentos, se coloca un punto antes y después de la inicial que identifica al personaje; los blancos separan las coplas que se convierten en unidades de percepción visual, como ocurre con la disposición de las composiciones de cancionero; incluso en una ocasión, en la Farsa de Pravos y Antona, la escena en que el Soldado define al amor («Es amor transformación...») aparece en la princeps de 1514 precedida por el epígrafe, destacado con un calderón, "Diffinición de amor» tal y como sucede tantas veces en el desarrollo de esas composiciones poéticas de los cancioneros, cuyo contenido se divide en epígrafes («Invocación», «Comparación», etc.). De la misma manera se señalan, separadas de las coplas, algunas marcas de estructura externa, tales como el fin de la obra, o la incorporación del villancico de cierre o su posible variación: "Otro villancico del mesmo acto" (Farsa o quasi comedia de doncella, pastor y caballero, fol. B4 vo). En definitiva, podríamos confirmar la intuición de Alberto Blecua (2012: 341) al relacionar la puntuación del Auto de la Pasión de Alonso del Campo con la tradición lírica. La escasa puntuación de Lucas Fernández responde a la tradición cancioneril fijada por el Cancionero de Enzina.

Algo parecido a lo que ocurre con la ausencia de didascalias explícitas. Las escasas didascalias explícitas — además del argumento inicial de cada pieza, que recoge el dramatis personae con su caracterización social, y algunas indicaciones de representación (orden de salidas y entradas, espacios, etc.)- se separan del texto mediante blancos, al margen izquierdo ancho de la columna correspondiente, señalado por las iniciales de los interlocutores, y se preceden en ocasiones de un calderón, que tiene así función no meramente ornamental, sino específicamente distintiva de elementos de representación para la lectura. Pero se emplean en ellas los mismos tipos góticos que en el resto del texto.

Escasos elementos tipográficos son estos, en cualquier caso, para ayudar al lector a leer con la oralidad implícita del texto teatral y su transformación imaginativa en evento.

Quizá, cuando Enzina pensara en la edición de su Cancionero, o Fernández en la de su colección de Farsas (o Torres en sus comedias para la Propalladia), prepararían un original para la imprenta a partir del manuscrito que pudieron usar en la organización de sus representaciones en las salas cortesanas; en ese manuscrito habría quizá indicaciones para la puesta en escena (o no, puesto que ellos mismos debieron encargarse de dirigir la representación). Ese original de imprenta desde el manuscrito inicial habría sufrido un proceso de revisión que piensa ya en el lector y no en el espectador, proceso que se completaría en la imprenta, como habría ocurrido con el original de La Celestina. Quizá haya que pensar que la escasez de didascalias explícitas en los impresos teatrales del XVI no responda sin más a la tosca o primitiva teatralidad de los autores, sino que sería

remos como tal el espacio blanco de separación entre coplas. Sobre la puntación del verso y los 
la consecuencia de ese proceso de traslado del teatro al texto, como un resultado, por lo tanto, de las circunstancias de transmisión. El autor del original ofrece al impresor solamente aquello que considera imprescindible para el lector y para la preservación del texto. Y el impresor adopta modelos conocidos de géneros no dramáticos o de textos dramáticos de la tradición clásica en boga. ${ }^{39}$

Pero esto es, sin otros testimonios, una mera hipótesis.

Quizá para suplir esa carencia de direcciones escénicas, que el lector debería deducir de la lectura del diálogo, algunos impresos teatrales incorporan grabados, como habían hecho las primeras ediciones terencianas (ver arriba n. 21).

Los grabados de los frontispicios son — según Chartier- sustitutos de la representación en la lectura, pues representan escenarios, vestuario, atrezo y gestos que ayudan a imaginar la acción y concentran la atención del lector en una escena (Chartier 1999: 37). ${ }^{40}$ Aznar Grasa (1992) al hacer el repaso de las ediciones ilustradas en la Salamanca del siglo Xvi constata la presencia de grabados en tres ediciones teatrales: Juan Sedeño, Tragicomedia de Calisto y Melibea en verso..., Salamanca, Pedro de Castro 1540; Sancho de Muñón, Tragicomedia de Lisandro y Roselia... Salamanca, Juan de Junta 1542, 4 y Fernando de Rojas, Tragicomedia de Calixto y Melibea... Salamanca, En casa de Juan y Andrés Renaut, A costa de Claudio Curlet, librero, en 1590. Al hacer la clasificación de las ediciones con grabados distingue los de carácter decorativo, de identificación del impresor, autor o dedicatario, los científicos o explicativos de conceptos, y los grabados acordes con el contenido del texto, "que condicionan de manera determinante la imagen que el lector se hace de un personaje o de una determinada situación (...) personajes y escenas de algunas obras de ficción»; este sería el caso de los grabados en los impresos teatrales, cuando tratan de transmitir la construcción de un espacio escenográfico. ${ }^{41}$

39. Para Chambers, — pensando, claro, en un teatro posterior - la abundancia de didascalias en una obra impresa sería indicio de que se trabajó en la imprenta a partir de un original de compañía; esas indicaciones escénicas estaban pensadas para la representación, y solo secundariamente para estimular la imaginación del lector ("They are primarily directions for the stage itself; it is only incidentally that they also serve to stimulate the reader's imagination by indicating the action with which the lines before him would have been accompanied in a representation», Chambers, 1951, vol. III: 195). Anota el caso de una obra, The Birth of Hercules de 1597 en cuyo manuscrito una segunda mano añadió direcciones escénicas, con la nota «Notae marginales inserviant dirigendae histrionicae», (Chambers, 1951, vol. IV: 4).
Gilman (1954/1955: 72): «It would seem that when Roxas sent his manuscript to Burgos in 1499 or thereabouts, it was assimilated to that printing tradition which had already grown up around the comedies of Terence».

40. ¿Puede ser un indicio de la utilidad «escénica» de estos tacos el hecho de que el hato del representante Gaspar de Oropesa que edita Pedro Cátedra contenga entre los textos que se inventarían «diez y nueve quadernos de obras que heran de un libro grande luminadas»? (Cátedra 2006: 503).

41. Aznar Grasa (1992: 80). Algo similar encontramos en las relaciones de fiestas, tan comunes a lo largo de los siglos XVI y XVII, en muchas de las cuales se incorporan grabados que tratan de poner ante los ojos del lector, es decir, representar, los elementos espectaculares de la cele- 
Las ilustraciones con estampas grabadas reproducen en los impresos teatrales del siglo XVI, es cierto, tipos convencionales y repetidos desde la ficción sentimental (dama, galán vieja, etc.) que son además intercambiables y aparecen en obras distintas, pasando de unos libros a otros; pero igualmente convencional podría ser el modo de representar determinadas escenas, e igualmente convencionales son los tipos teatrales representados. ${ }^{42}$ Naturalmente, un impresor no encargaría grabados nuevos para la impresión de un texto teatral, sino que echaría mano de los que tuviese disponibles (que pasan así de un impreso a otro), pero trataría de construir con ellos para el lector una posible escenografía, que no tiene por qué remitir a una representación «real» de la pieza que edita. Pero esto no descalifica la voluntad de ofrecer con la imprenta aquello que la representación da y el libro impreso no. El teatro había quedado vinculado en el mundo de la fiesta religiosa o cortesana, no tanto a la palabra como a la fuerza visual de efectos, adornos y accesorios; quizá el impresor, al incorporar imágenes al impreso teatral buscara no perder en el traslado al papel el hábito de esa mirada. ${ }^{43}$

De lo que no cabe duda es del intento de estas imágenes de establecer la relación con el texto a través de la ilustración y la propuesta de una lectura visual del mismo, a partir de la cual el lector puede reconstruir signos de la representación de los que carece en la lectura: caracterización de los personajes por su edad, por su vestuario, por su condición social; localización escénica en espacio urbano o en espacio rural; interacción gestual de los personajes, elementos del atrezo, etc. ${ }^{44}$

En el caso de La Celestina, por ejemplo, muchas de las ediciones antiguas optan por la selección de un fragmento escénico para ilustrar el inicio de los actos con un grabado que pone ante los ojos del lector aquello que el espectador podría tener a la vista en una representación. La construcción de un escenario, la gestualidad de los personajes son eminentemente teatrales, y esto es lo que debe destacarse más que su «fuerza narrativa» o la búsqueda de sus valores simbólicos (en las puertas, por ejemplo se ha querido ver una forma simbólica de representación del traspaso del himen melibeo). ${ }^{45}$ La edición de Joffre (Rojas, 1514) mezcla grabados

bración: arcos de triunfo, túmulos y otro tipo de escenografía efímera, acompañada de las inscripciones, lemas y versos que las ilustraban. 42. Ver Fernández Valladares (2012: 114-124) y el esclarecedor apéndice sobre la distribución de los grabados xilográficos de Celestina (1499) en sus diferentes apariciones (124-126).

43. Ver Warburg, 2005: 306.

44. Resulta muy interesante el repaso que hace Clifford Davidson (1991), muy especialmente para nuestro propósito las pp. 128-141, «Illustrations in Printed playbooks»: «when attempting to visualize a scene in drama, the printer drew directly on traditional tableaux in the visual arts as these were represented by blocks available to his print shop", (Davidson, 1991: 135a). Stone Peters (2000: 368, n. 31) repasa el sentido escénico de las ilustraciones del Terencio de Trechsel en 1493, y en relación con la Celestina de 1499, Rodríguez Solás (2009). 45. Montero, 2005. Ver Joseph Snow (1987) y Erna Berndt Kelley, (1993); un repaso al estado de la cuestión puede verse en el capítulo 8 , «La iconografía de La Celestina», de la tesis doctoral de Fernando Carmona Ruiz (2007: 320-332), así como su artículo de (2011). Infantes (2010: 15) en su brillante argumentación no toma en consideración una posible vinculación escénica 
muy convencionales, con la típica galería de personajes aislados, estereotipados e intercambiables, y elementos paisajísticos también repetidos, con otros grabados de indudable fuerza escenográfica, como el mismo de la portada, o aquellos que representan para el lector momentos culminantes, donde hay auténtica interacción de los personajes en creación de un espacio lúdico teatral. ${ }^{46}$

En apoyo del sentido escenográfico de los grabados, debemos considerar la ilustración con que se inicia el auto IV de La Celestina en la edición de Burgos, 1499:

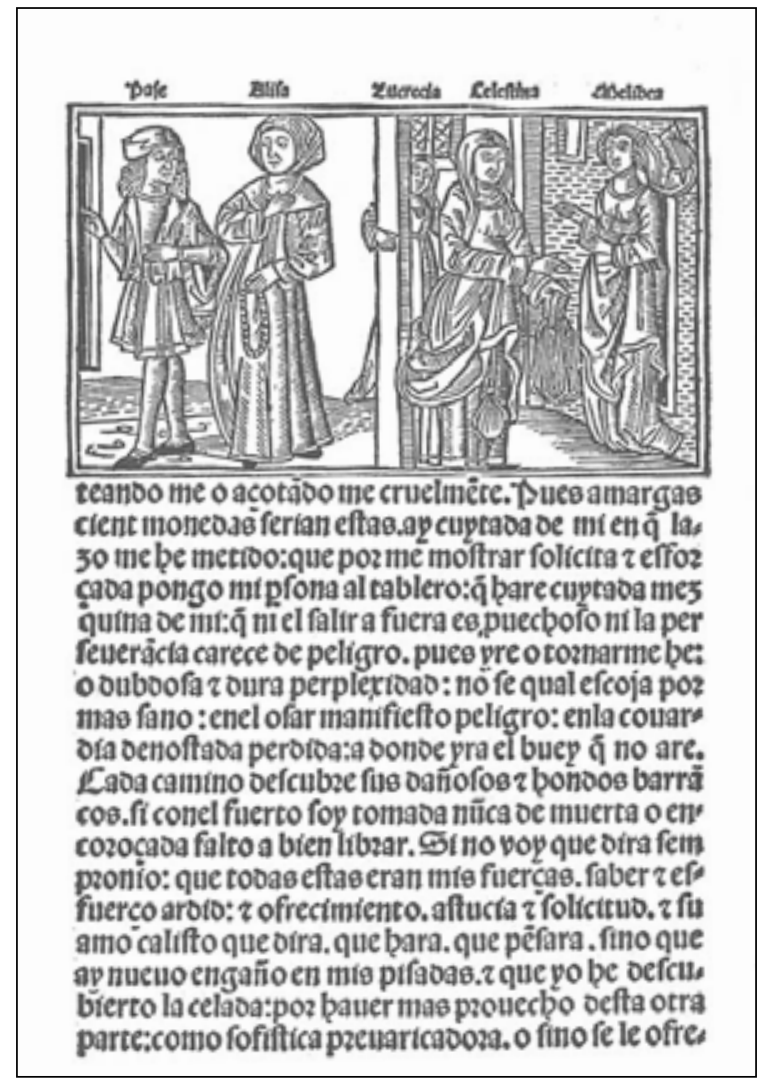

Comedia de Calisto y Melibea, Burgos, 1499, fol. d1v

de los grabados como elemento de atractivo y originalidad para un comprador de un texto teatral. Tampoco lo hace Mercedes Fernández Valladares, en un trabajo brillante y fundamental para asentar las bases del análisis biblioiconográfico, en el que dedica no pocas reflexiones a la Celestina burgalesa (Fernández Valladares 2012). 46. Pueden verse, por ejemplo, los grabados en el final del acto XII la muerte de Celestina (fol, 50v), en el XIII el ajusticiamiento de Pármeno y Sempronio (fol. 51r), en el XIV la subida por la escala al jardín de Melibea (fol. 52v, que se repite en el acto XIX, fol. 63r, justo antes de la escena de la muerte de Calisto, representada en el fol. 64r), y finalmente en el acto XXI el suicidio de Melibea (fol. 66r), (Rojas, 1514). 
Siguiendo la convención representativa, el grabado se refiere a los personajes que intervienen en el auto, estableciendo para ellos un vestuario distintivo (p. e., tocados para la dueńa y la madre), un atrezo (el rosario de Alisa, el cordón de Celestina...), un espacio escénico (segmentado por la puerta de separación: la calle o campo para Alisa; el interior o portal para el encuentro de Celestina y Melibea con la mirada de Lucrecia), un decorado (puertas, ventanas, celosías) y una interrelación gestual con manos y miradas. Lo que sorprende de este grabado concreto es la incorporación de ese personaje, señalado como «paje», a la izquierda del grabado, que no interviene en el texto y que solamente aparece por referencia indirecta:

ALISA: Hija Melibea, quédese esta mujer honrada contigo, que ya me paresce que es tarde para ir a visitar a mi hermana (...), y también que viene su paje a llamarme... (sub mío). ${ }^{47}$

En el grabado acompaña con verosimilitud a la dama Alisa, marcándole con la mano derecha el camino que deben seguir sus pasos, alejándose de la escena principal en donde ocurre el encuentro de Celestina y Melibea. Este paje es un verdadero figurante, un personaje con pleno sentido en el espacio de la representación, pero no en el espacio del texto. El grabador está representando la acción desde una perspectiva visual, escenográfica podríamos decir, más que desde una perspectiva textual. El mismo personaje, identificado en el rótulo sobre la figura, carente de parlamento en el texto dramático, puede verse en el grabado del auto X (fol. 62r). Ciertamente, el caso del grabador de la edición de Burgos 1499 es un caso excepcional de representación visual de lo representado, pero ilustra muy bien el sentido teatral de los tacos, casi como una didascalia explícita. ${ }^{48}$

Las imágenes que circulaban en los impresos teatrales clásicos reflejaban - aunque de forma ditorsionada a veces - lo que los humanistas estaban intentando hacer en los escenarios a lo largo de Europa; y quienes se encargaban de esas producciones eran con frecuencia los mismos que se encargaron de llevar los textos a la imprenta. ${ }^{49}$

47. La Celestina, acto IV, escena $4^{\mathrm{a}}$, (Rojas, 2006: 76).

48. «El conjunto de estos xilograbados — por su estilo, de un único artista- es una lectura visual completa de la acción narrativa en forma frecuentemente dramática.», dice de los grabados de Burgos 1499 Snow (1987: 260). En este estudio se pueden encontrar más ejemplos de otros detalles de la atención visual al progreso de la acción por parte del ilustrador. Pollard (1912: 163) relaciona los grabados de la edición de Burgos con los del impresor alemán Grüninger para su Terencio, Estrasburgo, 1496. Sobre Terencio y la Celestina ver ahora Rodríguez-Solás (2009) y Cull (2010). Puede verse la espléndida colección de 28 grabados, de gran realismo, en la edición alemana de La Celestina (Rojas, 1520) por Wirsung, Ausburg, 1520 en la web del British Museum en línea, http://www.britishmuseum. org/research/search_the_collection_database/ search_results.aspx?search Text=Celestina\&from $\mathrm{ADBC}=$ ad\&toADBC=ad\&numpages=10\&ori $\mathrm{g}=\% 2$ fresearch $\% 2$ fsearch_the_collection_database.aspx\&currentPage=1 (consulta 5 de febrero, 2013); los grabados de Hans Weiditz han sido recientemente estudiados por Carmona Ruiz (2011). Infantes (2010: 31) considera los grabados de la edición de 1499 en relación con los del impreso del Oliveros de Castilla, salido el mismo año del mismo taller y en las dificultades de composición del impreso que suponían.

49. Traduzco la idea de Julie Stone Peters, 
Otro caso interesante puede señalarse en la 'mise en page' del Auto de la Pasión de Lucas Fernández, en la princeps mencionada de las Farsas del salmantino, de Salamanca por Lorenzo de Liondedei, (Fernández, 1514). Allí, un taco ilustra el último folio, precediendo al villancico dialogado final $-D i$, ¿por qué mueres en cruz, / universal Redemptor? -- $-A y$, que por ti, pecador!, (fol. a6v). El villancico completa el pasaje de adoración general del monumento, buscando el mismo efecto de conmoción por la música al que invitaría en escena una actitud que el texto ha previsto, como se recoge esta vez explícitamente en la correspondiente didascalia:

PEDRO: Todos, todos le adoremos / y alabemos

DIONISIO: ¿¿Y donde está? MATEO: Veslo allí

(Aqui se han de hincar de rodillas los recitadores delante del monumento, cantando esta canción y villancico en canto de órgano). Adorámoste, Señor, / Dios y hombre verdadero (...) Di, por qué mueres en cruz...

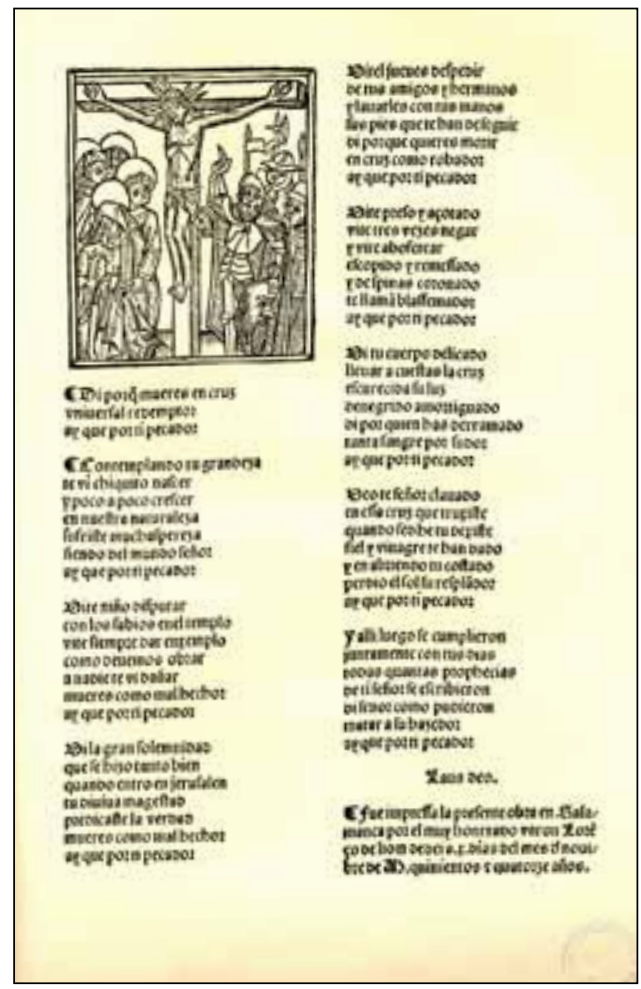

Lucas Fernández, Auto de la Pasión, Salamanca, 1514, fol. a6v

(2000:5), donde se refiere como ejemplo a la implicación de Badius Ascensius en montajes de Terencio en Ferrara en torno a 1480 y en la edición del comediógrafo latino por Trechsel en
Lyon en 1493 (ver Stone 2000: 316, n. 16). Sobre la presencia de Terencio en la Universidad de Salamanca ver Framiñán 2011 y Paolini 2011, y arriba n. 21 . 
Sin embargo, a pesar de su ubicación en el impreso, el grabado parece remitir a una escena inmediatamente anterior, donde se propone un mecanismo de apariencia escénica, tras las palabras de Mateo, en otro momento culminante del pathos escénico:

Los ribaldos y sayones

en tierra hincaron la cruz

vimosla entre dos ladrones

más alta que los lançones

resplandeciendo con luz.

Començamosla adorar

con divina reverencia

y adorando lamentar

y cantar

la gloria de su excelencia

Aquí se ha de demostrar o descobrir una cruz repente a desora la qual han de adorar todos los recitadores hincados de rodillas cantando en canto de órgano $O$ crux ave spes unica... (Fernández, 1514, fol a4r). ${ }^{50}$

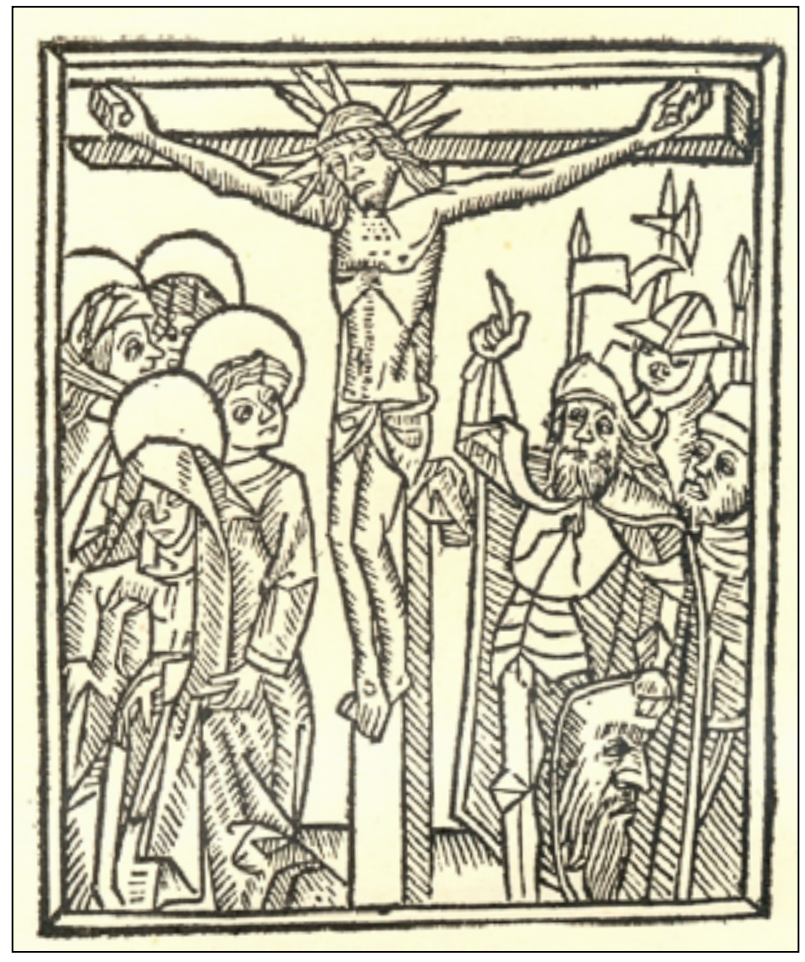

Lucas Fernández, Auto de la Pasión, Salamanca, 1514, fol. a6v, detalle

50. Hermenegildo (1986: 711) se planteaba si las didascalias del texto de Lucas Fernández eran 
La elección de los grupos de personajes en la estampa no se corresponde con el piadoso calvario convencional con María y Juan a cada lado de la cruz. Se eligen, en disposición más compleja, dos grupos diversos, según es frecuente en crucifixiones pintadas de finales del Xv y comienzos del xvi para dar cabida a todos los personajes del relato evangélico: lamentación a la izquierda, soldados a la derecha. En el grupo de la izquierda se trata de representar gestualmente el dolor con los apóstoles con aureola, que acompañan a una virgen dolorosa desvanecida, que apenas puede ser sostenida por el joven Juan. En el grupo de la derecha, sobre el fondo de lanceros, un personaje en primer plano, que mira hacia arriba y apunta, en actitud parlante, con el índice de su mano derecha al crucificado en un gesto teatral que acompañaría sus palabras, mientras sostiene en la izquierda un elemento de atrezo (un escudo con rostro), parece representar al centurión que exclama: «verdaderamente este era hijo de Dios» (Mt. 27, 54, Mc. 15, 39, Lc, 23, 47-). ${ }^{51}$

Llama la atención el evidente anacronismo en la caracterización del vestuario del grupo de personajes de la derecha; la altura de la Cruz, por encima de las lanzas, las llamativas potencias del Cristo que parecen rayos luminosos, se adaptan a la descripción que hace Mateo en el texto de Lucas Fernández («más alta que los lanzones / resplandeciendo con luz»). Todos ellos son rasgos que convierten la escena grabada en un icono de la representación, muy específicamente de la apariencia repentina de la cruz, prevista como efecto catártico en la obra.

La puesta en página suple para el lector la apariencia escénica con un taco, que actúa a modo de ventana abierta a los ojos del que lee, con una iconografía ciertamente convencional, pero que se adapta al momento escénico que se quiere representar favoreciendo la conmoción, como pudo ocurrir con el efecto de la apariencia en escena, y teatralizando (representado ante los ojos) el texto. La devoción por los ojos es un hábito social que se hace presente en el espacio de la capilla y la iglesia (a través de retablos y tablas) y en el de la representación a través de las apariencias y que el impreso ha sentido la necesidad de recoger. ${ }^{52}$

auténticas didascalias de representación o simples ayudas ofrecidas al lector; en el impreso parecen ambas cosas. Monique Martinez Thomas, (Golopentia y Martinez, 1994, p. 152) considera las didascalias del teatro de Juan del Enzina como elementos que en el impreso hacen crónica de una representación real ofrecida, pero se convierten al tiempo en instrucciones para futuras representaciones.

51. El gesto de mirar hacia arriba y apuntar al cielo es el apropiado, según la predicación, para hablar de cosas celestiales o divinas, como recuerda Baxandall (2000: 90); por su parte Victor Stoichita relaciona el gesto con el mecanismo de la integración de la palabra y la imagen «haciéndolas a la vez accesibles al espectador» (Stoichita,
1996: 16). El grabado reproduce - toscamente- una disposición semejante a la del grabado de 1511 de Alberto Durero, "Cristo en la Cruz", $\mathrm{n}^{\circ} 24$ de la serie de ilustraciones conocida como «Pequeña Pasión», estampas del libro de devoción ilustrado Passio Christi ab Alberto Durer Nurenbergensi effigiata cum varii generis carminibus Fratris Benedicti Chelidonii Musophili. Nuremberg: Albrecht Dürer, 1511. Pueden verse la Crucifixión de Gerard David (1490) en 1 Museo Thyssen de Madrid, o la de Grünewald (1501) en el Öffentliche Kunstsammlung de Basel.

52. Sobre el hábito social de la mirada devota ver Baxandall (2000: 60). El grabado de esta edición de las Farsas lo utiliza antes el mismo impresor Lorenzo de Liondedei en la obra Lec- 
El hecho cierto de que los impresos teatrales del siglo XviI (en partes o sueltas) carezcan de este tipo de ilustraciones, debe hacernos pensar en una definitiva institucionalización del género en el impreso, con espacios bien delimitados, precisamente porque el teatro en escena vive en España un auge sin precedentes y el formato impreso para la lectura del teatro ha quedado fijado..$^{53} \mathrm{El}$ momento y las circunstancias del teatro español en el primer Renacimiento es otro, y a la novedad del impreso habría que añadir la novedad de un teatro más allá de las formas de teatralidad tradicionales. Se justificaría así el que no se quisiera prescindir entonces, en su traslación al impreso, del hábito social de la mirada que implicaba en el teatro.

En conclusión, la consideración de algunas de las circunstancias de la materialización de los textos teatrales en el silencioso mundo del manuscrito y del impreso muestra el proceso de pérdida y transformación implicado en la «institucionalización» de un género concebido inicialmente para el bullicioso espacio de la representación y que aun no ha fijado su apariencia editorial.

La falta de formatos propios, el modelo de los cancioneros poéticos, el sacrificio de la oralidad en una puntuación inexpresiva, la búsqueda de elementos de apoyo visual para el lector, que respetan inicialmente la costumbre de la mirada social sobre el teatro, desacostumbrada al impreso, son algunos de los rasgos que debemos ir definiendo en la forma de imprimir las obras teatrales del renacimiento espańol, en el camino hacia la fijación de convenciones de impresión del texto teatral, que sirvan simultaneamente al lector y al hombre de teatro en la construcción del sentido de la obra.

La fijación del gusto por el impreso teatral, construido desde la mise en page de los clásicos griegos y romanos, es un proceso en formación en los años finales del siglo xv y en los primeros años del siglo xvi. La edición impresa en Venecia en 1553 de La Celestina, cuya puesta en página hemos analizado, nos habla ya de una casi definitiva «institucionalización» del texto teatral en la imprenta para la lectura. Al fin y al cabo, la imprenta parece estar en el corazón mismo del renacimiento del teatro en el siglo xvi, y el paso del teatro al texto a través de la imprenta al tiempo que suponía un sacrificio de elementos integrantes de su naturaleza oral, aseguraba también la posibilidad de la repetición de los textos en nuevas representaciones y su perdurabilidad en la lectura individual o colectiva. ${ }^{54}$

tiones quorundam sanctorum iamdiu elucubrate. Salmanticae, 1513, con función ilustrativa devocional, antecediendo a un poema latino de Passio Domini (Lectiones, 1513; Ruiz Fidalgo, 1994, I: 230, item 99). Valero (2003: 191) localiza el mismo grabado en la edición de los Libri minores de Hans Gysser en Salamanca c. 1501; explica el grabado del Auto como ilustrativo de uno de los momentos de «iconización visual fuerte» en la dramatización de la obra. 53. Sobre el declive del libro teatral ilustrado en el siglo XVII, ver Stone Peters 2000: 62-63. 54. Es la opinión de Julie Stone Peters, (2000: 1): «Print was at the heart of the Renaissance theatrical revival». Sin embargo, los textos dramáticos impresos en el siglo xv y en el temprano XVI — dice- apenas tienen elementos de diferenciación genérica (2000: 23). Similar 
Cobrar conciencia de los mecanismos que el impreso puede poner en juego para salvaguardar la naturaleza doble del género teatral, contribuye a afrontar la consideración de los mismos desde una perspectiva enriquecedora, modificando nuestra manera habitual de tratar estos textos como productos exclusivamente literarios dentro de la institución llamada historia literaria, indeferenciados de otros géneros sin ese componente específico del teatro, que en los orígenes de su historia impresa cuesta identificar. Cobrar conciencia en definitiva de los mecanismos habilitados para el desarrollo del teatro como institución, aunque nos movamos casi siempre para este primer teatro renacentista «en las regiones sombrías de la conjetura». 55

opinión había expresado Chambers: «A historian of the stage owes so much of his material to the printed copied of plays, with their title pages, their prefatory epistles, and their stagedirections, that he can hardly be dispensed from giving some account of the process by which plays got into print», (Chambers, 1951, vol. III: 158).

55. "We are moving in shadowy regions of conjecture» (Chambers, 1951, vol. III: 8). 


\section{Bibliografía}

Aznar Grasa, José Manuel 1992, «La ilustración del libro impreso en Salamanca. Siglos XV y XVI. Análisis cuantitativo y temático», en El libro antiguo español. Actas del segundo Coloquio Internacional, María Luisa López Vidriero y Pedro M. Cátedra, eds. Salamanca, Ediciones Universidad Salamanca, 61-95.

Baxandall, Michael, 2000 Pintura y vida cotidiana en el Renacimiento, Barcelona, Editorial Gustavo Gili.

BÉCARES, Vicente 1998, "Compras de libros para la biblioteca universitaria salmantina del Renacimiento", en El libro antiguo español. Coleccionismo y Bibliotecas (siglos XV-XVIII), ed. $M^{a}$ Isabel Hernández González, Salamanca, Ediciones Universidad Salamanca, 83-135.

Berndt Kelley, Erna 1993 «Mute commentaries on a text: the illustrations of the Comedia de Calisto y Melibea», en I.A. Corfis y Joseph T. Snow (eds.), Fernando de Rojas and Celestina. Approaching the fifth centenary, Madison, The Hispanic Seminar of Medieval Studies, 193-228.

Blecua, Alberto 2010, «Sobre el MS de Palacio de La Celestina», en La Celestina. Ecdotica e interpretazione, Francisco Lobera, ed., Roma, Bagatto Libri, 17-42.

—, 2012, «Sobre la (no) puntuación en los textos dramáticos del Siglo de Oro», en Estudios de crítica textual, Madrid, Gredos, 319-342.

Cacho, M.T. y Blanca Periñán 2006, "La Farsa de la Constanza recuperada», Rivista di Filologia e Letteratura Ispaniche IX, 9-29.

Carmona Ruiz, Fernando, 2007 La recepción de la Celestina en Alemania en el siglo XVI, Universität Freiburg, tesis doctoral, <http://ethesis.unifr.ch/theses/ downloads.php?file=CarmonaF.pdf $>$ (consulta 21 de enero 2013).

—, 2011, «La cuestión iconográfica de la Celestina y el legado de Hans Weiditz», eHumanista 19, 79-112.

<http://www.ehumanista.ucsb.edu/volumes/volume_19/pdfs/articles/ 3\%20ehumanista19.celestina.carmonaruiz.pdf>

Cátedra García, Pedro Manuel (2005), El "Colloquio de los divinos amores», atribuido a Juan de Timoneda, Salamanca, SEMYR.

—, 2006, Tres colloquios pastoriles de Juan de Vergara y Lope de Rueda, (Valencia, 1567. Ahora de nuevo editados y estudiados por Pedro M. Cátedra, con (pro) puesta de escena de Emilio de Miguel, San Millán de la Cogolla, Cilengua.

Chambers, E. K 1951, The Elizabethan Stage, Oxford, Clarendon Press, $1^{\text {a }}$ ed. 1923. 4 vols.

Chartier, Roger 1999 Publishing Drama in Early Modern Europe, London, The Bristish Library.

—, 2000, «La pluma, el taller y la voz. Entre historia cultural y crítica textual», en Francisco Rico, dir., Imprenta y crítica textual en el Siglo de Oro, Valladolid, Centro para la Edición de la Clásicos Españoles, 243-257.

Chaytor, H.J. 1967, From Script to Print: An Introduction to Medieval Vernacular Literature, New York. 
Comedia (s.a.), Comedia a lo pastoril para la noche de Navidad nuevamente compuesta, Biblioteca Nacional de España, MSS 16058.

Corfis, Ivy A. 1993, "Celestina as Drama: Commentary by a $16^{\text {th }}$ Century Reader", Romance Philology 47, 33-47.

Crawford, J.P. W. 1911, "Comedia a lo pastoril para la noche de Navidad», Revue Hispanique 24, 497-541.

Cull, John T. 2010, "A Possible Influence on the Burgos 1499 "Celestina» Illustrations. The German 1486 Translation of Terence's «Eunuchus»", La Coronica 38:2, 137-162.

D’Artors, Florence 2010, «¿Es posible una poética de la parte de comedias? Cuestiones, dificultades, perspectivas», Criticón 108, 7-24.

Davidson, Clifford 1991, Illustrations of the Stage and Acting in England to 1580, Michigan, Medieval Institute Publications, Kalamazoo.

Delicado, Francisco 2006, La lozana andaluza, ed. de Folke Gernert, Barcelona, Galaxia Gutenberg.

DiCamillo, Ottavio 2005, "Consideraciones sobre La Celestina y las instituciones dramatúrgicas del humanismo en lengua vulgar», en La Celestina 14991999. Selected Papers from the International Congress in Commemoration of the Quincentennial Aniversary of La Celestina, New York, November 17-19, 1999. Edited by Ottavio DiCamillo\&John O’Neill, New York, págs. 53-74.

Enzina, Juan del 1496, Cancionero de las obras de Juan del Enzina, Salamanca, Hans Gysser, en <http://www.cervantesvirtual.com/obra-visor/cancionerode-juan-del-encina-primera-edicion-1496--0/html/ffadf59c-82b1-11dfacc7-002185ce6064.html> (consulta 22 de enero, 2013).

Estatutos hechos en la Universidad de Salamanca, 1538 Salamanca, Pedro de Castro. <http://brumario.usal.es/search $\sim \mathrm{S} 6$ *spi?/tEstatutos/testatutos/1\%2 $\mathrm{C} 170 \% 2 \mathrm{C} 207 \% 2 \mathrm{CB} /$ frameset $\& \mathrm{FF}=$ testatutos $+1538 \& 1 \% 2 \mathrm{C} 1 \% 2 \mathrm{C}>$ (consulta 23 de enero 2013).

Faulhaber, Charles B. 1990, "Celestina de Palacio: Madrid, Biblioteca de Palacio, MS 1520», Celestinesca, XIV:2, 3-39.

—, 1992), «The Heredia-Zabalburu Copy of the Tragicomedia de Calisto y Melibea «Sevilla 1502» (i.e.: Rome, Marcellus Silber, c.a. 1516», Celestinesca, $16,25-34$.

FERNÁNDEZ, Lucas, 1514, Farsas y Églogas al modo y estilo pastoril y castellano fechas por Lucas Fernández salmantino nuevamente impressas, Salamanca, Lorenzo de Liom dedei

Fernández de Heredia, Juan 1524, Farça hecha a manera de visita de las damas valençianas, mss $2621 \mathrm{BNE}$, ff. 122r-146v.

$<$ http://bibliotecadigitalhispanica.bne.es/view/action/nmets. do? DOCCHOICE $=1788114 . x \mathrm{ml} \& \mathrm{dvs}=1360694225680 \sim 72 \&$ locale $=$ en_US\&search_terms $=\&$ adjacency $=\& V I E W E R . U R L=/$ view/action/nmets. do?\&DELIVERY_RULE_ID=4\&usePid1=true \&usePid2=true> (consulta 12 de febrero, 2013). 
Fernández Valladares, Mercedes 2012, «Biblioiconografía y literatura popular impresa: la ilustración de los pliegos sueltos burgaleses (o de babuines y estampas celestinescas)", eHumanista 21, 87-131.

$<$ http://www.ehumanista.ucsb.edu/volumes/volume_21/pdfs/mongraphic\%20issue/4\%20eHumanista21.fernandez.pdf>

Ferreres, Rafael 1975, ed. Juan Fernández de Heredia, Obras, Madrid, Espasa Calpe, Clásicos Castellanos.

Framiñ́n de Miguel, Ma Jesús 2011 Teatro en Salamanca (1500-1627). Estudio y documentos, tesis doctoral, Salamanca, Universidad de Salamanca

García-Bermejo Giner, Miguel M. 1996, Catálogo del teatro español del siglo $X V I$, Salamanca, Ediciones Universidad Salamanca.

—, 1998 «Creación del impreso teatral: texto y práctica dramática», en A. Redondo, Pedro M. Cátedra y Ma Luisa López Vidriero, eds., El escrito en el Siglo de Oro. Prácticas y representaciones, Salamanca, Ediciones Universidad de Salamanca, 111-128.

Gillet, Joseph E. 1943, 1946, 1951, 1961, Propalladia and other Works of Bartolome Torres Naharro, edited by Joseph E. Gillet, Pennsylvania, Bryn Mawr, 4 vols.

Gilman, Stephen 1954/1955, «The Argumentos to La Celestina», Romance Philology, 8, 71-78.

Giuliani, Luigi 2010, «La Parte de comedias como género editorial», Criticón 108, 25-36.

Golopentia, Sandra y Monique Martinez Thomas 1994), Voir les didascalies, Paris, CRIC Université de Toulouse-Le Mirail, ibéricas 3.

Griffin, Clive 1988, «Un curioso inventario de libros de 1528», en El libro antiguo español. Actas del primer Coloquio Internacional, María Luisa López Vidriero y Pedro M. Cátedra, eds. Salamanca, Ediciones Universidad, 189-224.

—, 1998, «El inventario del almacén de libros del impresor Juan Cromberger: Sevilla, 1540", en El libro antiguo español. Coleccionismo y Bibliotecas (siglos $X V-X V I I I)$, ed. Ma Isabel Hernández González, Salamanca, Ediciones Universidad Salamanca, 257-373.

HasenOHR, Geneviève 1990, "Les manuscrits théâtraux», en Henri Jean Martin et Jean Vezin, dirs., Mise en page et mise en texte du libre manuscrit, París, Editions du Cercle, 335-340.

Hermenegildo, Alfredo 1986, "Acercamiento al estudio de las didascalias del teatro castellano primitivo: Lucas Fernández», en Actas del VII Congreso de la AIH, Madrid, Istmo, 709-729.

Howard-Hill, T.H. 1990, "The Evolution of the Form of Plays in English During the Renaissance", Renaissance Quarterly 43, 112-145.

IbáŃEz PÉRez, Ma J. 1990, «La traducción de Anfitrión del doctor López de Villalobos", Minerva 4, 255-276.

Infantes, Víctor 2010, La trama impresa de Celestina. Ediciones, libros y autógrafos de Fernando de Rojas, Madrid, Visor. 
LaLou, Elisabeth 1991 «Les Rolets de Théâtre. Étude Codicologique», en Théatre et Spectacles hier et aujourd'hui. Moyen Âge et Renaissance, Paris, Editions du CTHS, 51-71.

Lectiones 1513, Lectiones quorundam sanctorum iamdiu elucubrate. Salmanticae, Laurentius Liondedei. <http://brumario.usal.es/tmp/_webpac2_1723971. 250481> (consulta 25 de enero 2013).

Lida de Malkiel, Ma Rosa 1984, "La técnica dramática de La Celestina», en Homenaje a Ana María Barrenechea, ed. Lia Schwartz e Isaias Lerner, Madrid, Castalia, 281-292.

López de Villalobos, Francisco 1550, Libro intitulado los problemas de Villalobos que trata de cuerpos naturales y morales (...) Y la comedia Amphytrion, Sevilla, Christóbal Álvarez, M.D.L. Comedia en los fols. XLVI a LXI vo (cuadernos $\mathrm{g}-\mathrm{h}$ ).

McPheeters, D. W. 1956, "Alonso de Proaza and the Celestina», Hispanic Review 24, 13-25.

Melveena McKendrick 1989, Theatre in Spain 1490-1700, Cambridge, Cambridge University Press.

Miguel Martínez, Emilio de 1996, La Celestina de Rojas, Madrid, Gredos.

—, 2006, "(Pro)puesta en escena», en Cátedra (2006), 467-489.

—, 2009 «La Celestina, Madre rehusada del teatro español», en Germán Vega, (ed.) De La Celestina a la Vida es sueño, Salamanca, Col. Olmedo Clásico, 15-44.

—, 2013, De teatro. La preparación del espectador, Kassel Reichenberger.

Misiti, Maria Cristina 1992), «Alcune rare edizioni spagnole publicate a Roma da Antonio Martínez de Salamanca», en El libro antiguo español. Actas del segundo Coloquio Internacional, María Luisa López Vidriero y Pedro M. Cátedra, eds. Salamanca, Ediciones Universidad, 307-323.

Montero, Ana Isabel 2005, «A penetrable text? Illustration and transgression in the 1499 (?) edition of Celestina», Word \& Image, 21: 3, 41-55.

Norton, F.J. 1966), Printing in Spain 1501-1520, Cambridge, Cambridge University Press.

Olezz, Joan 1998, «La comedia a fantasía y los orígenes de la práctica escénica cortesana», en J. Ma Díez Borque (ed.), Teatro cortesano en la España de los Austrias, Madrid, Cuadernos de Teatro Clásico 10, 1998, 13-30.

Olivetro, Georgina 1998), «Ejemplares de Celestina de la colección FoulchéDelbosc en la Biblioteca Nacional de la República Argentina», Celestinesca 22, 67-74.

PaOlini, Devid 2011, «Sobre un tópico equivocado (las representaciones de las comedias de Plauto y Terencio en España a finales del siglo xv) y Celestina», Celestinesca 35, 67-83.

Parkes, M.B. 1992, Pause and Effect. An Introduction to the History of Punctuation in the West, Scolar Press, Cambridge.

Pérez de Oliva, Fernán, 1586, Las Obras del Maestro Fernán Pérez de Oliva, En Córdoba por Gabriel Ramos Bejarano. 
$<$ http://books.google.es/books?id=5ptK5h2XP8gC\&printsec=frontcover\& $\mathrm{dq}=$ Perez+de+Oliva\&hl=es\&sa=X\&ei=XLf_ULO2IIjI0AWk1YHgDA\&ve $\mathrm{d}=0 \mathrm{CDIQ6AEwAA}>$ (consulta 23 de enero 2013).

Pérez Priego, Miguel Ángel 1998 «La Transmisión de la obra dramática en el siglo XVI», en Estudios sobre teatro del Renacimiento, Madrid, UNED, 157-169.

—, 2011, «El teatro del Renacimiento: perspectiva crítica», Edad de Oro XXX 2011, 245-255.

Periñán, Blanca y Togelio Reyes 2012, ed. Cristóbal de Castillejo, Farsa de la Costanza, Madrid, Cátedra.

Pollard, Alfred W. 1912, Fine Books, New York: G. P. Putnam's Sons, London: Methuen \& Co. Ltd. <http://www.gutenberg.org/files/35494/35494-h/ 35494-h.htm\#page143>, (consulta el 4 de febrero 2013).

Pontón, Gonzalo, 2012, «Figuras sin paisaje: las dramatis personae en las ediciones tempranas de La Celestina», en Fosalba, Eugenia y Gonzalo Pontón, coord., La escondida senda. Estudios en homenaje a Alberto Blecua, Barcelona, Castalia, 61- 84

Profeti, Maria Grazia 1982 «Luogo teatrale e scrittura: il teatro di Juan del Encina", Lingüistica e Letteratura VII, 155-172.

—, 1996 "Comedias representadas — textos literarios: los problemas ecdóticos», en C. Hernández Valcárcel (ed.), Teatro, historia y sociedad, Murcia-Ciudad Juárez, Universidad de Murcia-Universidad Autónoma de Ciudad Juárez, 205-216.

Quintero, María Cristina 1990, «The Interaction of Text and Culture in Spanish Renaissance Translations of Plautus' Amphytriuo", Bulletin of Hispanic Studies 67, 235-252.

Rodríguez-SolÁs, David 2009, "A la vanguardia del libro ilustrado: El Terencio de Lyon 1493 y La Celestina de Burgos 1499), Bulletin of Spanish Studies, 86:1, 1-17.

Rojas, Fernando de 1499, Comedia de Calisto y Melibea... Burgos, Fadrique de Basilea. <http://bib.cervantesvirtual.com/servlet/SirveObras/125849608 23477162109435/index.htm> (consulta 23 de enero 2013).

-, 1502), Tragicomedia de Calisto y Melibea, Sevilla, Cromberger (i.e., Roma, Marcellus Silber c. 1516 $<$ http://bib.cervantesvirtual.com/servlet/SirveObras/017159633267060 42980035/index.htm> (consulta 23 de enero 2013)

-, 1506, Tragicocomedia [sic] di Calisto e Melibea nouamente traducta de spagnolo in italiano idioma [per Alphonso Hordognez], Roma, per Eucharium Silber $<$ http://bdh.bne.es/bnesearch/CompleteSearch.do?field=titulo\&text=Celestina \&showYearItems=\&exact=on\&textH =\&advanced=false\&completeText=\&page Size=1\&pageSizeAbrv=10\&pageNumber=3> (consulta el 5 de febrero de 2013).

—, 1514, Tragicomedia de Calisto y Melibea, Valencia, Juan Joffre, <http://bib. cervantesvirtual.com/servlet/SirveObras/34696280982381641354679/ index.htm> (consulta 28 de enero 2013). 
-, 1520, Ain Hipsche Tragedia vo zwaien liebhabendn mentschen ainem Ritter Calixstus vn ainer Edln junckfrawen Melibia genat ..., Augspurg, durch Sigismund Grym vnd Marx Wirsung. Disponible en Biblioteca Dioscórides de la UCM <http://alfama.sim.ucm.es/dioscorides/consulta_libro.asp?ref $=\mathrm{I} 26424228$ \&idioma $=0>$ (consulta 13 de febrero 2013).

—, 1553, Tragicomedia de Calisto y Melibea (...) Dirigida al Illustre Sennor Don Bartholome de Vargas y con somma diligentia corrigida por el S. Alonso de Ulloa; e Impressa en guisa hasta aqui nunca uista. Impressa en Venecia en casa de Gabriel Giolito de Ferrariis y sus hermanos en el anno del s. MDLIII.

—, 1590, Tragicomedia de Calisto y Melibea, En Salamanca, En casa de Juan y Andrés Renaut, A costa de Claudio Curlet, librero $<$ http://bdh.bne.es/bnesearch/CompleteSearch.do?field=titulo\&text=Celestina \&showYearItems $=\&$ exact $=$ on\&textH $=\&$ advanced=false\&completeText $=\& p a$ geSize=1\&pageSizeAbrv=10\&pageNumber $=20>$ (consulta 5 de febrero 2013).

—, 2000 La Celestina. Tragicomedia de Calisto y Melibea, ed. Francisco Rico et al., Barcelona, Crítica.

—, 2006, La Celestina, ed. Emilio de Miguel Martínez, Madrid, Turner, Biblioteca Castro.

Rueda, Lope de 1576, Las Primeras dos elegantes y graciosas comedias del excellente poeta y representante Lope de Rueda, Sevilla, Alonso de la Barrera. <http://www. cervantesvirtual.com/servlet/SirveObras/13537408912807495222202/ index.htm> (consulta 29 de enero 2013).

Ruiz Fidalgo, Lorenzo 1994, La imprenta en Salamanca (1501-1600), Madrid, Arco Libros, 3 vols.

SAEnger, Paul 1982 «Silent Reading: Its Impact on Late Medieval Script and Society", Viator 13, 367-414.

SAntiago, Ramón, 1996, «La puntuación según Nebrija», Dicenda 14, 273 284.

—, 1998, «Apuntes para la historia de la puntuación en los siglos XVI y XVII», en J.M. Blecua, Juan Gutiérrez y Lidia Sala, eds., Estudios de grafemática en el dominio hispano, Salamanca, Ediciones Universidad, 243-280.

Sebastián Mediavilla, Fidel 2003 «Las primeras ediciones de La Celestina y su puntuación», BRAE 83 (2003), 113-135.

—, 2007, Puntuación, humanismo e imprenta en el Siglo de Oro, Vigo, Academia del Hispanismo.

—, 2010, «Puntuación y stemma de La Celestina», Bulletin Hispanique, 112, 509-529.

SÉneCA, Lucio Anneo 1514, L. Annei Senecae Tragoediae pristinae integritati restitutae, Parisiis, 1514 (BUS, 12004).

Shergold, N.D. 1967, A History of the Spanish Stage from Medieval Times until the End of the Seventeenth Century, Oxford, Clarendon Press.

Snow, Joseph 1987, «La iconografía de tres Celestinas tempranas (Burgos, 1499, Sevilla, 1518, Valencia, 1514. Unas observaciones», Dicenda 6, 255-277. 
—, 2001, «Historia de la recepción de Celestina: 1499-1822, II (1499-1600), Celestinesca 25, 199-282.

Stoichita, Victor I. 1996, El ojo mistico. Pintura y visión religiosa en el Siglo de Oro español, Madrid, Alianza Forma.

Stone Peters, Julie 2000, Theatre of the Book 1480-1880. Print, Text and Performance in Europe, Oxford, Oxford University Press.

—, 2004, "Theater and Book in the History of Memory: Materializing Mnemosyne in the Age of Print», Modern Philology 102, 179-206.

Terencio 1499 Comoediae cum commentariis Aelii Donati, Guidonis Juvenalis, Johannis Calphurnii et Jodoci Badii Ascensii, en Venecia, 1499, Biblioteca General de la Universidad de Salamanca I/256 <http://brumario.usal.es/ record $=$ b1855028 $>$ (consulta 22 de enero 2013).

Torres Naharro, Bartoloméde 1517, Propalladia, En Napoles por Ioan Pasqueto de Sallo, <http://www.kb.dk/en/kb/nb/ha/boghistorie/propalladia_intro. html> (consulta 23 de enero 2013).

—, 1545 Propalladia, Sevilla, por Andrés de Burgos, <http://www.cervantes virtual.com/servlet/SirveObras/23584063210158309632679/index.htm> (consulta 29 de enero 2013)

—, 1994, Obra completa, ed. Miguel Ángel Pérez Priego, Madrid, Turner Biblioteca Castro.

Urrea, Pedro Manuel 2012, Cancionero, ed. Ma Isabel Toro Pascua, Zaragoza, Prensas Universitarias, 3 vols.

VACCARI, Debora, 2006 I «papeles de actor» della Biblioteca Nacional de Madrid : catalogo e studio, Florencia, Alinea.

VAlero, Juan Miguel 2003, «La pasión según Lucas Fernández», La Coronica $31,117-216$.

VANEGAS, Alejo 1531, Tractadode OrtographiayAccentosen lastreslenguasprincipales, Toledo,LázaroSalvagoGinovés, <http://bibliotecadigitalhispanica.bne.es:80/ webclient/DeliveryManager?pid=1866479\&custom_att_2=simple_ viewer> (consulta 19 de febrero de 2013).

Vázquez Estévez, Ana 1995, Impresos dramáticos españoles de los siglos XVI y XVII en las bibliotecas de Barcelona, Kassel, Reichenberger.

—, 2003, «La Comedia Sepúlveda: notas acerca de su rescate y adquisición por la Biblioteca del Instituto del Teatro", Revista Galega de Teatro, 35, 39-41.

VEGA, Lope de 1613, La dama boba, manuscrito autógrafo, BN <http://biblioteca digitalhispanica.bne.es/view/action/nmets.do?DOCCHOICE=198696.xm $1 \& d v s=1358859758080-999 \&$ locale=es\&search_terms $=\&$ adjacency $=\&$ VIEWER_URL=/view/action/nmets.do?\&DELIVERY_RULE_ ID=4\&usePid1 =true\&usePid2=true> (consulta 22 de enero de 2013).

—, 1621 El dómine Lucas, Parte XVII de Comedias, en TESO, Chadwick-Healey, 1998.

—, 1623, La campana de Aragón, Parte XVIII de Comedias, en TESO, Chadwick-Healey, 1998. 
Vega García-Luengos, Germán 2010, "Sobre la identidad de las partes de comedias", Criticon, 108, 57-78.

WARBURG, Aby, 2005 «El vestuario de los intermezzi de 1589», 1895), en El renacimiento del paganismo. Aportaciones a la historia cultural del Renacimiento europeo, Madrid, Alianza Editorial, 291-329.

Webber, Edwin J. 1956 «The Literary Reputation of Terence and Plautus in Medieval and Pre-Renaissance Spain», Hispanic Review 24, 191-206.

—, 1957/1958, «Manuscripts and Early Printed Editions of Terence and Plautus in Spain», Romance Philology 11, 29.39, p. 34.

Werstine, Paul 2013, Early Modern Playhouse Manuscripts and the Editing of Shakespeare, Cambridge, Cambridge University Press.

Zanger, Abby E. 1988, «Paralyzing Performance: Sacrificing Theater on the Altar of Publication", Stanford French Review, Fall-Winter, 169-188. 
